\title{
Rapid Response Small Machining NNR Project 703025
}

Federal Manufacturing \& Technologies

Tim Kanies

KCP-613-8533

Published November 2008

Final Report

Approved for public release; distribution is unlimited.



Prepared under prime contract DE-ACO4-01AL66850 for the

United States Department of Energy 


\section{DISCLAIMER}

This report was prepared as an account of work sponsored by an agency of the United States Government. Neither the United States Government nor any agency thereof, nor any of their employees, makes any warranty, express or implied, or assumes any legal liability or responsibility for the accuracy, completeness, or usefulness of any information, apparatus, product, or process disclosed, or represents that its use would not infringe privately owned rights. Reference herein to any specific commercial product, process or service by trade names, trademark, manufacturer, or otherwise, does not necessarily constitute or imply its endorsement, recommendation or favoring by the United States Government or any agency thereof. The views and opinions of authors expressed herein do not necessarily state or reflect those of the United States Government or any agency thereof.

All data prepared, analyzed and presented has been developed in a specific context of work and was prepared for internal evaluation and use pursuant to that work authorized under the reference contract. Reference herein to any specific commercial product, process or service by trade name, trademark, manufacturer, or otherwise, does not necessarily constitute or imply its endorsement, recommendation or favoring by the United States Government, any agency thereof or Honeywell Federal Manufacturing \& Technologies, LLC.

Printed in the United States of America.

This report has been reproduced from the best available copy.

Available to DOE and DOE contractors from the Office of Scientific and Technical Information, P.O. Box 62, Oak Ridge, Tennessee 37831; prices available from (865) 576-8401, FTS 626-8401.

Available to the public from the National Technical Information Service, U.S. Department of Commerce, 5285 Port Royal, Rd., Springfield, Virginia 22161, (703) 487-4650.

A prime contractor with the United States Department of Energy under Contract Number DE-AC04-O1AL66850

\author{
Honeywell Federal Manufacturing \& Technologies \\ P.O. Box 419159 \\ Kansas City, Missouri, 64141-6159
}




\section{Honeywell}

KCP-613-xxxx Distribution Category UC-xx

Approved for public release; distribution is unlimited.

RAPID RESPONSE SMALL MACHINING NNR PROJECT 703025

Tim Kanies

Published November 2008

Final Report 



\section{Contents}

Section

Page

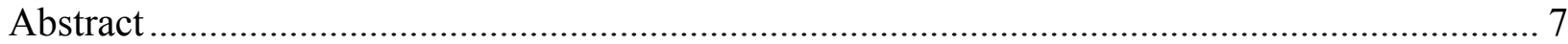

Summary

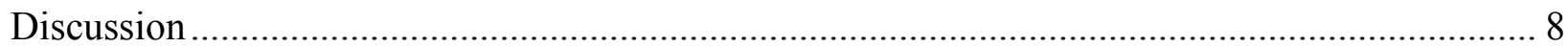

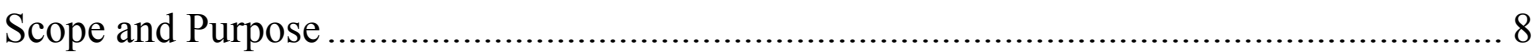

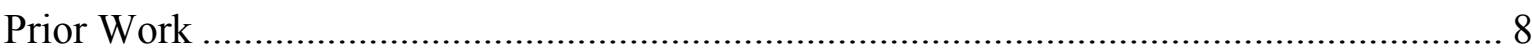

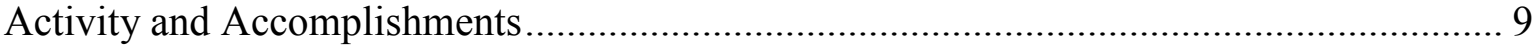

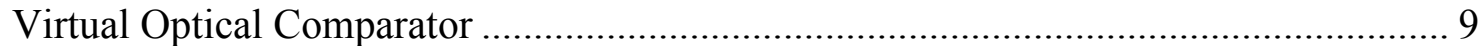

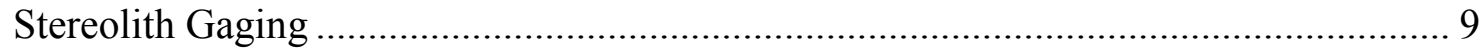

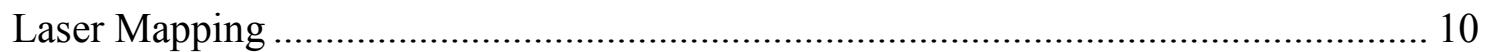

Agile Machining Processes Standardization............................................................ 12

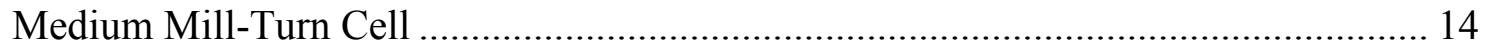

Small Swiss-Style Mill-Turn .............................................................................. 15

NC Tape Generation Streamlining....................................................................... 16

Pallet System Study for Special Applications Machining ............................................. 17

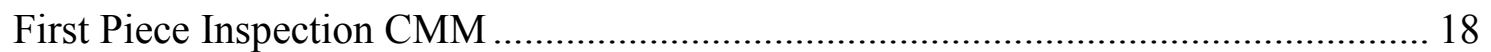



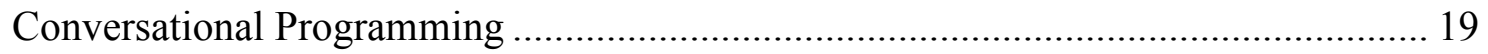

Heat Exchanger Kellenberger Hydraulic System ........................................................ 19

Chiller/Metalworking Fluid Systems on Precision Lathes ............................................ 22



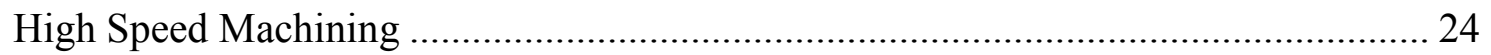

Reprocess the Fireset Housing to the Department ........................................................ 24

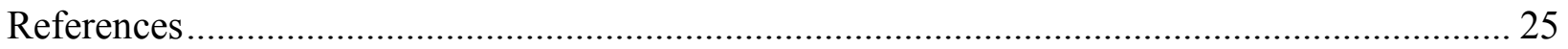

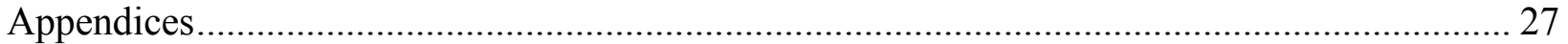

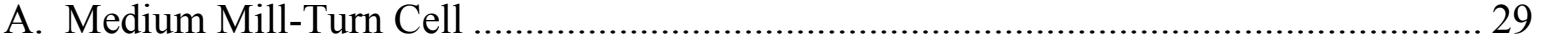

B. Report for Rapid Response Project for the STAR Mill-Turn Cell.................................. 43

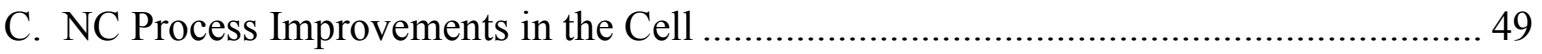

D. Pallet System Study for Special Applications Machining …………………………..... 55 


\section{Figures}

Figure

Page

Figure 1: Non-Contact Laser Measurement......................................................................... 12

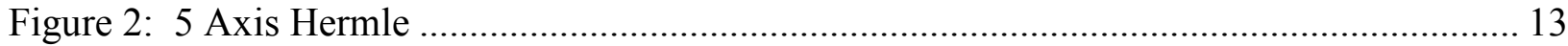

Figure 3: External view of one of the Gildemeister CTX 320 mill-turn machines. ................... 14

Figure 4: External view of the Relocated 32mm STAR mill-turn machine. ............................. 16

Figure 5: Delphin Pallet System from System 3R ................................................................ 17

Figure 6: Actual Machine and Silma XG Off-line Programming Software .............................. 18

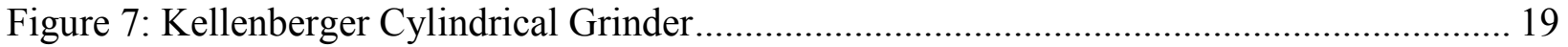

Figure 8: Supply and Return Lines Entering Machine Frame ................................................ 20

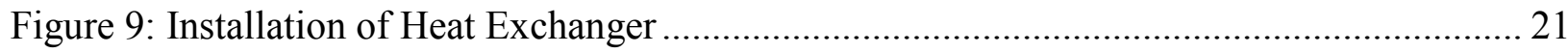

Figure 10: Reverse Side of Heat Exchanger .................................................................... 21

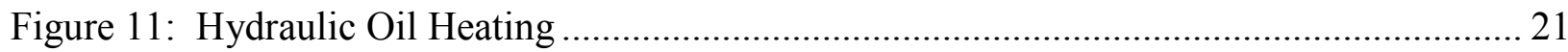

Figure 12: Chiller Installed on American Lathe .................................................................. 22

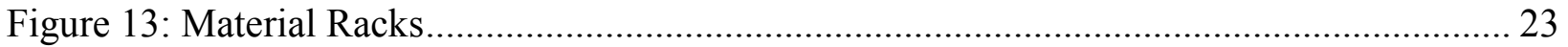

Figure 14: Lean Cell Setup Carts ............................................................................................... 24 


\begin{abstract}
This project was an effort to develop a machining area for small sized parts that is capable of delivering product with a quick response time. This entailed focusing efforts on leaning out specific work cells that would result in overall improvement to the entire machining area. This effort involved securing the most efficient available technologies for these areas. In the end, this incorporated preparing the small machining area for transformation to a new facility.
\end{abstract}

\title{
Summary
}

Predating this project was an effort to update some major pieces of capital equipment and tooling to accomplish a leaner machining environment. However, funding was not available, so this project had to determine a new plan of attack where new machine tools were not the foundation of the Agile effort. So, the early stages of the project determined the new areas of focus that should be worked to obtain the most impact for the time, effort, and funding available.

The project identified several areas of similar working characteristics that resided inside the small machining and inspection areas. These areas were further defined and it was decided to concentrate on these areas deeming them "work cells" and "teams" in order to focus on processes and technology to improve response time. These cells and teams evolved during the project into subproject teams and some even spun off into their own Advanced Design and Production Technologies (ADAPT) or Non-Nuclear Readiness (NNR) campaign projects. The following sub-teams are discussed either in detail within this report or in a stand alone report. 


\section{Discussion}

\section{Scope and Purpose}

The scope of this project was to develop a machining area (for small metal parts) that is capable of delivering product in less flow time by focusing on quick response, using a reduced supporting crew, and applying the most efficient available technologies. The intent was to evaluate processes, equipment, and infrastructure for ways to reduce production cycles in the small machining area. The project needed to identify and lean out production and inspection methods. It also needed to determine if new equipment should be purchased or existing equipment excessed or relocated to increase effectiveness. Once these determinations were made and carried out, the new methodology and processes were to demonstrate their abilities.

The efforts of this project were originally to affect several areas of the business. Floor space and flow time was to be reduced. An improved maintenance program was to be considered. An improved relationship between process engineering, numerical control (NC) analysts, design agency and manufacturing was needed to increase responsiveness. Then when the new plant initiative came about, this all very easily evolved into transforming the small machining area into a department readying itself to be relocated in an entirely new facility. Thus, the project was slightly redirected in the last project task agreement and became more of an effort to equip work cells and address issues of concern identified by the sourcing initiative.

\section{Prior Work}

Predating this project was an effort to update some major pieces of capital equipment and tooling to accomplish a leaner machining environment. However, funding was not available, so this project had to determine a new plan of attack where new machine tools were not the foundation of the Agile effort. So, the early stages of the project determined the new areas of focus that should be worked to obtain the most impact for the time, effort, and funding available.

The project identified several areas of similar working characteristics that resided inside the small machining and inspection areas. These areas were further defined and it was decided to concentrate on these areas deeming them "work cells" in order to focus on processes and technology to improve response time. The original work cells totaled seven and were the Large Machining Cell, Small Swiss-Style Mill-Turn Cell, Medium Mill-Turn Cell, Mill Cell, Gas Transfer System (GTS) Cell, Electronic Design Manufacturing (EDM) Cell, and the Grinding Cell. Additionally several groups of support were identified and consisted of the Numerical Control Team, Capital Equipment Team, Manual Coordinate Measuring Machine (CMM) Team, and the Business Practices Team.

The background for this project and how it ties to the entire Agile machining effort can be found in a report dated 02/21/2005, titled "Preliminary Report By the Agile Machining and Inspection Thrust Area Team On a Funding Proposal for FY06-FY08.” 


\section{Activity and Accomplishments}

\section{$\underline{\text { Virtual Optical Comparator }}$}

The Virtual Optical Comparator was conceived during the procurement of design gages for a program mechanism. The Dual Stronglink Mechanism has similar features. Piece part designs included many critical features that are machined on the face of a part. Traditionally these features are checked on optical comparators using reflected light to illuminate the part surfaces. The part tolerance required the use of at least $50 \mathrm{X}$ magnification. At this magnification the light intensity of the best comparators are marginal to see reflected part features. The edge breaks can be confused with the part edge. The 50X magnification makes many part images too large for a 30 -inch comparator. This required the use of expensive fixtures so the part could be shifted to check portions of the part separately. This is a slow and tedious process.

The Virtual Optical Comparator (VOC) uses a charged coupled devices (CCD) camera to obtain the image of the part feature. This allows part surfaces to be more easily illuminated and viewed. Parts would be mounted on a precision X-Y stage so that the part image can be viewed in one set up. A computer-aided drawing (CAD) image of a traditional comparator chart would be overlaid over the part image on the monitor. It could be set and rotated to fit it to the part similar to traditional comparator charts. The part features can then be checked within the CAD image lines the same way traditional charts are used. The advantages of this system are that there is superior edge detection. No vinyl charts are procured or inspected. The part size and expensive fixtures are no longer a concern because of the long range of the $\mathrm{X}-\mathrm{Y}$ table; as the table moves the CAD image will move precisely in sync. Product redesigns require only changes to the $\mathrm{CAD}$ image. The inspection process is more ergonomic by allowing the operator to view the part sitting at a desk rather than standing over a 30 inch screen. The procurement cost for the VOC will be less than a traditional comparator with a much smaller footprint with less maintenance and energy requirements. It was funded by the NNR Rapid Response Small Machining project and a report ${ }^{1}$ has been written to document the technical information.

\section{Stereolith Gaging}

One of the rapid response subprojects was to investigate if stereolithography could be used to fabricate durable tooling used in the acceptance of product. In the case illustrated below a stereolithography model made from a polymer that formed a harder, more dimensionally stable solid was made. The cavity represents the acceptable dimensional envelope of the assembly as specified by the product drawing. As long as the assembly did not exceed the cavity void space it was acceptable. In this case the tube assembly is placed in the cavity and a straight edge drawn across the surface. As long as the straight edge does not contact the tube assembly, the assembly is in compliance and acceptable dimensionally.

So far fives gages have been fabricated. All of the sterolithography gages have been accepted by the design agency during qualification. Periodic checking has shown they are still within 
dimensional tolerance. In addition the gages are so inexpensive two of them have also been made into shipping containers to protect the components for storage and shipment to the field.

The stereolithography gages have been submitted as productivity improvement project. Quotes obtained to fabricate these gages from aluminum would have cost over $\$ 113 \mathrm{~K}$. Gages made from sterolithography cost only $\$ 7 \mathrm{~K}$. Over $\$ 106 \mathrm{~K}$ was saved in procurement cost to the customer.
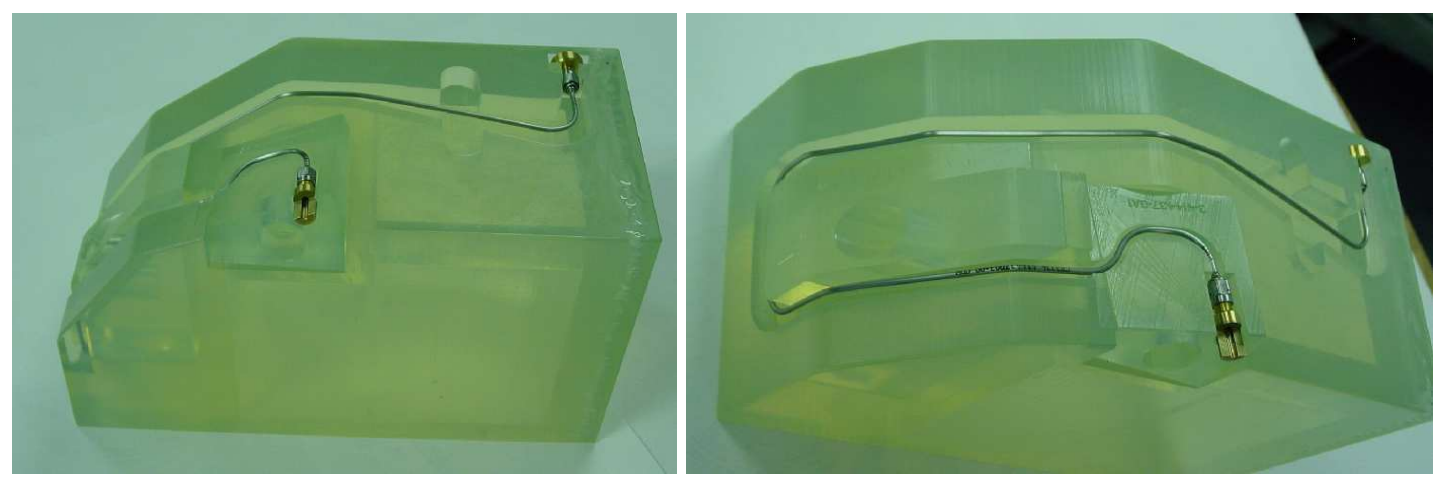

\section{Laser Mapping}

The purpose of this project ${ }^{2}$ was to characterize the performance of laser probes on a carbon syntactic foam part and to develop a measuring system if the probe response and measuring system total error budget was adequate to meet a 4:1 tolerance ratio measuring requirement.

In order to establish the system total error budget, a concept of the measuring system was derived. This system used conventional ball screw linear stages, air bearings, servo motors and controller, and precision linear scales. All components were to be mounted on precision ground mounts wherever possible. Best fabrication and assembly tolerances were added to the derived probe performance data, and the uncertainty for calibration of a reference master was included in the error budget analysis.

Part manufacturing tolerances were identified to determine the minimum 4:1 uncertainty ratio of the measurement system. This established a baseline requirement from which to determine the selected technology. A major concern was part impedance during the measurement. Another concern was repetitive handling, part staging, and operator influence of the measuring process. From this, an investigation of performance characteristics for various measuring and automation components began. Laser probes from Sunx, Keyence, and Micro-Epsilon were evaluated. It was quickly determined that the Micro-Epsilon laser probe head had superior performance because of its triangulation method which used a CCD camera and advanced algorithm to process the received laser data. Additionally, the Micro-Epsilon head used superior Zeiss optics, and corrected for optical errors. The measuring uncertainty and linearity of the micro-epsilon were conservatively rated and still met the 4:1 measuring ratios.

\section{Gage Development}

An outside order was placed to design and build the laser gage. The gage design would have an inner and outer linear axis with probe heads for each. Each linear axis would have a rotary axis to fine adjust the lasers as needed to optimize the laser performance for any angled surface or 
unpredicted response from the laser. Between the axes was a rotary table which would index the part for each profile sweep.

\section{Gage software}

A PC was added as part of the gage design to control the gage measurements and process the data. A software interface was provided to allow the user to enter a part number and run the part. The software also has selections to calibrate the gage, and a selection for limited engineering diagnostics. The software provided "hooks" to customize the inspection program for the specific part. Another interface was provided for inspection of the syntactic foam part. However, neither of these programs was intended to provide full "turn key" capability due to the unknown performance and requirements for each part.

\section{Software Calibration Routine}

The general concept of the gage did not provide "intelligence" about the part geometry. This required a transfer master to link part-specific precision coordinate measuring machine (CMM) geometry to the gage. The master was inspected in four equal sweeps at levels inspected on the part. The deviations of the master were loaded in the gage software as reference values. The gage measured the same points and associated its values with the calibrated master values. This enabled the software to accurately correct the actual values of measured parts. The software performs a best fit of the datum -B- diameter as required by the drawing and corrects all measured values to the new coordinate system. The values are reported on the screen, and a report of the screen is saved to a main and backup hard drive. Each part file is time stamped and named with the part serial number.

\section{Software Monitor Part Routine}

In addition to the calibration and part inspection routines, a monitor part utility was added. This utility allows a "loop closure" to be performed on each inspection run. The monitor part is an aluminum part with a flat polyurethane coating that simulates the part surface. When the gage is calibrated, the monitor part is run, and the result becomes the monitor part inspection baseline. This baseline is saved on the hard drive and every subsequent monitor part inspection is compared against the baseline data. In this way the gage can be monitored for changes with each inspection run, and part re-gaging will be kept to a minimum.

\section{Laser Probe Characterization}

The laser probe's greatest uncertainty is produced by specular reflection. This is a function of incident angle and material type. The laser does not do well with shiny objects and spherical geometries. Therefore, a number of tests were conducted with the laser probe to compare surface textures and coatings with the measured part. The objective was to create a master and monitor part that performed like the foam part. Measurements were made on a vapor blasted aluminum (dull semi-porous surface), an aluminum hard coat surface (flat black), a flat black epoxy coat on the aluminum, and a flat black polyurethane coat on aluminum. The greatest measuring uncertainty (specularity) was with the uncoated and hard coat surfaces. The best on-axis, low 
specular performance was from polyurethane, and this was the coating selected for the master and monitor part.



Figure 1: Non-Contact Laser Measurement

The gage was designed, built, and delivered. The gage was inspected and met all initial requirements. Considerable programming and documentation was done to tune the measuring system to gaging the carbon syntactic foam part. Programming included positioning the probe to defined target levels, part indexing, data alignment, and report generation. Programming was also added to extend the gage to measure additional features. The gage allows simultaneous measurement of inner and outer features, which cuts measuring time by half. The measuring process allows the part to set in its free state on the gage and scan at multiple levels. As part of a monitoring process, a monitor part (polyurethane coated aluminum) was made. The monitor part was designed to be run before and after each inspection lot. Using the monitor catches any gage performance issues before too much time is invested in inspection, and safeguards against acceptance of bad product.

The basic software interface is in place to include inspection of the carbon syntactic foam part. This software will be tuned as needed, and the engineering evaluation process will parallel the steps required for the original part. In addition, further investigation will look at extending the gage capabilities to scan in a rotational direction to inspect slots and vertical profiles.

Other applications may employ laser probes to measure and regulate coating thickness.

\section{$\underline{\text { Agile Machining Processes Standardization }}$}

This project was to incorporate lean manufacturing techniques into machining processes where milling is the majority of the work. The goals were aggressive, trying to reach a $60-80 \%$ on-time delivery/operational efficiency and to increase machine utilization by $50 \%$. Mill set up was targeted to increase setup efficiency to $75 \%$ and reduce fixture needs by $50 \%$. 


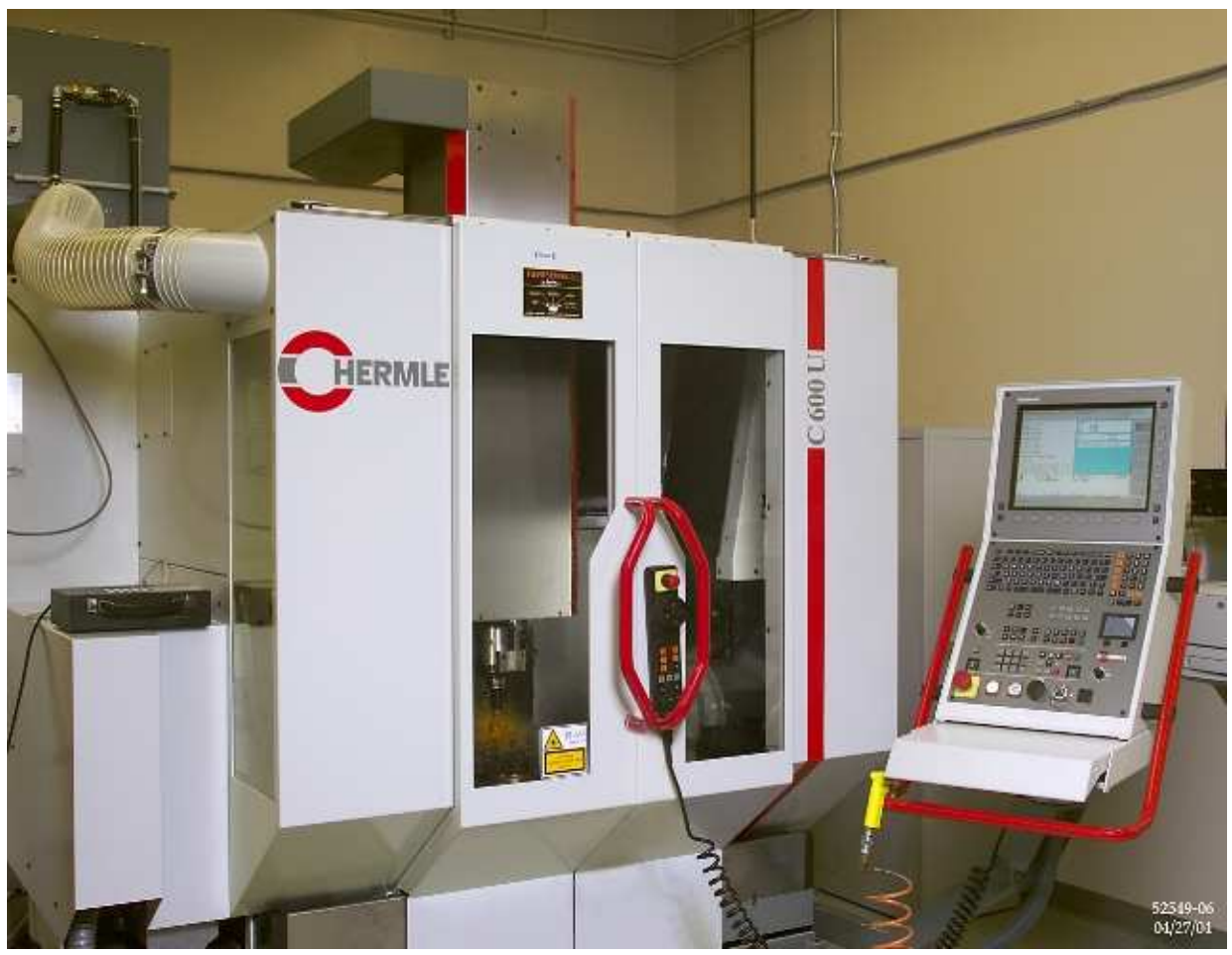

Figure 2: 5 Axis Hermle

The cell was formed with a flexible work staff by the formal assignment of engineers, NC analysts, production fabricators, and machinists. They attended formal lean training to promote communication and develop team dynamics. The team reduced rigidity in job descriptions creating a working environment based on the individual needs of the dedicated members. Ultimately the team instituted work practices and technology requirements to enable successful completion of their extensive goals.

Major efforts were made to cross train between job functions and to create experts within the cell structure. These experts could then cross train other people within the area. Four operators were trained. This method of training personnel was documented for repeatable use as machinists relocate due to manpower issues.

The team engineered the ability to have a low variation between setups and thus a low requirement for hard fixturing (a 75\% reduction in fixturing needs). The processes and procedures for fixturing were documented. The results were good with a setup efficiency average of $60-80 \%$ and setup times were reduced to 4 hours. Machine utilization increased $45 \%$ allowing more quantities of parts to be worked on this higher quality equipment. Cycle times were reduced enabling the cell to prove in new product quicker and to also use the machines for more small lot runs which is commonplace in the department.

Standardization of work was performed. Engineers, NC analysts and machinists all were assigned standard procedures that were developed as a team. Common information and tooling was documented as templates and reference materials on line. This resulted in a single source of information with common location of all files accessible from any computer in the plant. 
Other beneficial activities included working on the post processor to accept all machine functions and to reliably create a first issue, bug free, program; sharing with other cells what the team learned to optimize best work practices in their cell; and determining and procuring needed tooling to make the cell functional.

\section{Medium Mill-Turn Cell}

Many parts in production in the department had existing processes set up to use multiple machining operations to produce parts. The Medium Mill-Turn (MMT) Cell subproject focused on reprocessing many of those parts to utilize a Gildemeister mill-turn machine, in order to reduce the number of operations, setups, standard hours, and flow time. The parts that were reprocessed to the mill-turn cell required mostly turning operations, and some milling operations. Most of the parts either had existing processes on the Hardinge Superslant and/or CNC Chucker lathes in the department, or would have been processed on those machines if the mill-turn cell had not been implemented.

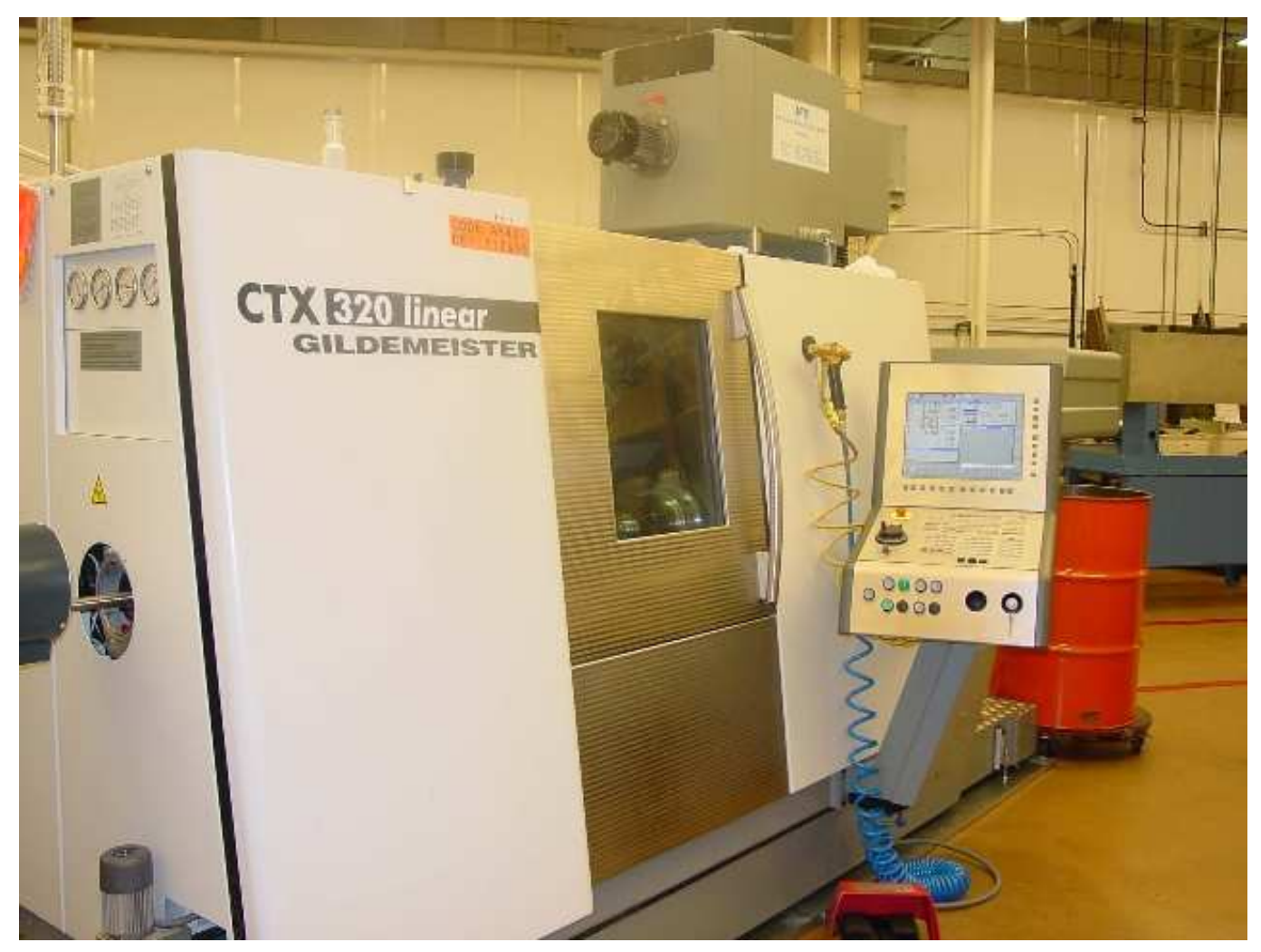

Figure 3: External view of one of the Gildemeister mill-turn machines.

In addition to reprocessing parts, the MMT cell incorporated many changes in the ways that work is performed. Beginning with the methods of designing the manufacturing processes and obtaining the required tooling and programming support, through proving in and improving the process during manufacturing, and then coordinating with final inspection to verify part quality earlier in the process, when improvements can produce greater results. 
The natural team for the Medium Mill-Turn cell consisted of two process engineers, an industrial engineer, two numerical control analysts, three machinists, and one Operations Team Manager (OTM). The team met on a regular basis to discuss various issues within the cell such as production schedules and priorities, technical challenges, lessons learned, and ideas to improve production efficiency and quality. The increased amount of communication between team members during the design phases of processing helps to identify and eliminate some problems early on, when changes are easier to make and defects can be avoided.

A total of 20 separate part numbers were reprocessed to the Gildemeister mill-turn machine in the department. In most cases, this action replaced multiple NC machining operations, as well as some manual operations, with a single $\mathrm{NC}$ machining operation. This reduced the number and length of setups, reduced total cycle time, and increased throughput.

The team developed a standard setup consisting of several tooling blocks, cutting tools, and inserts, and designated those as the default tools to have set up in the machine. This reduces the amount of time it takes to switch production from one part number to another, since most of the tools commonly used are already set up in the machine.

The work areas around each machine were reorganized so that turret blocks, tool holders, cutting inserts, and other tooling are kept in standard areas. Having the tools organized in this fashion makes it simpler to find tooling when needed, and also helps the operator know when they need to replenish a particular insert or tool, before they run out.

The MMT cell team completed the design and prove-in of a test part that can be used to check the accuracy and repeatability of the Gildemeister mill-turn machine. This alternative to the formal laser realignment process will save an estimated $\$ 13,000$ each year.

Standard hour reductions on parts produced in the cell resulted in a savings of approximately $\$ 22,000$ in FY06, $\$ 13,000$ in FY07, and an estimated $\$ 12,000$ in FY08. The forecast yield for the cylinder was raised in FY07 from $80 \%$ to $90 \%$ based on parts produced since implementation of the mill-turn cell. This resulted in a savings of approximately $\$ 7,000$ due to a reduction in projected scrap as well as the number of parts that would need to be started in the next 12 months in order to meet the needs of the next level assembly.

\section{$\underline{\text { Small Swiss-Style Mill-Turn }}$}

This project was initiated to reduce the part cycle time on the two STAR Swiss Mill-Turn machines by reducing the setup times and the actual machining times. The Rapid Response project funded the relocation of the existing 32MM STAR machine and initiated the procurement of the new 20 MM STAR. The machines were arranged in a mill-turn cell in preparation for placement in the new building and the potential for one machinist operating both machines. Listed in the accomplishments section of the report are the specific actions performed to accomplish the goals. Some of the performed work created savings through cycle time reduction, while other work created cost savings through the reduction of scrap. Of course, some of this work did not create any measurable cost savings, and some of it only made the machinist's job easier. 


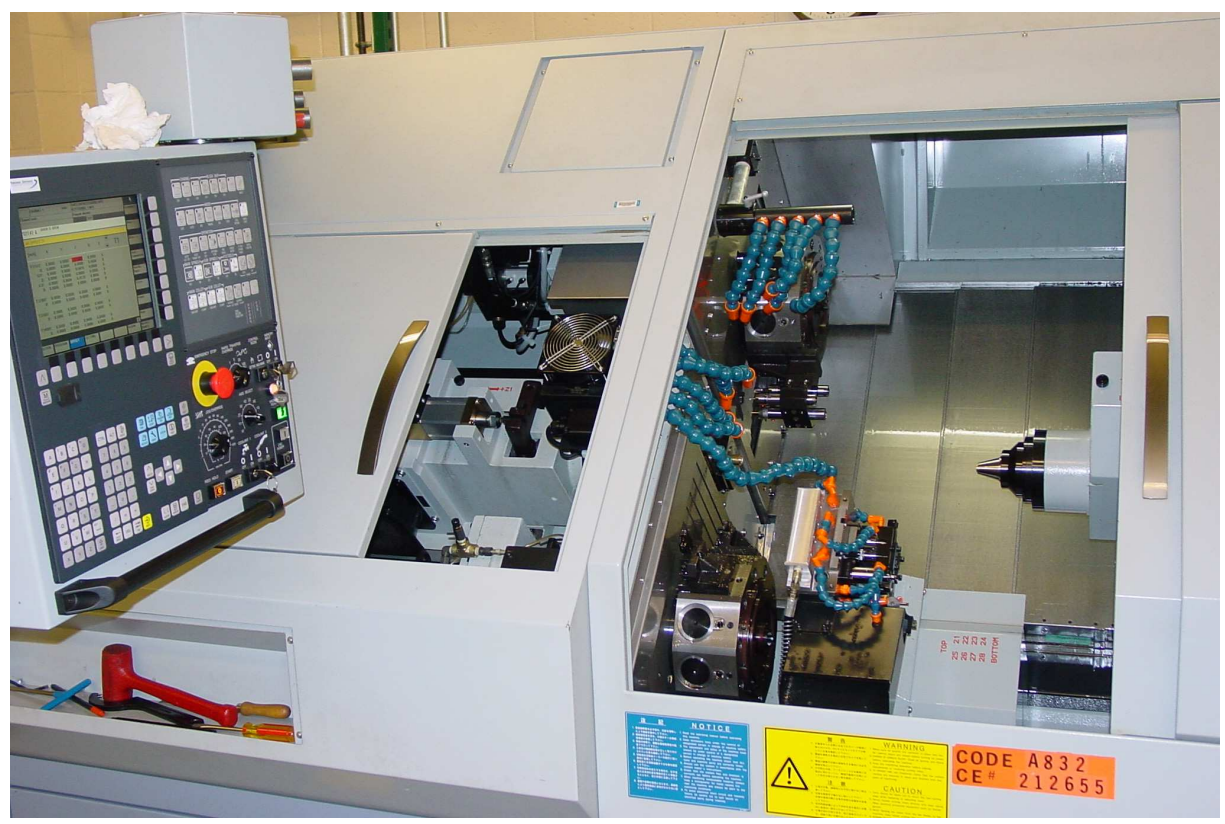

Figure 4: External view of the Relocated 32mm STAR mill-turn machine.

A total cycle time reduction of approximately 105 days on several STAR parts resulted from the stated work in the accomplishments section of this report. This equates to approximately $\$ 30,000$ worth of savings in the next year. In addition, scrap reduction savings totaling approximately $\$ 129,000$ emerged on several parts due to some of the other work performed on this project.

\section{$\underline{\text { NC Tape Generation Streamlining }}$}

The intent of this subproject is to analyze the business practices of the NC programming department and to identify and implement opportunities for improvement. A major goal of this subproject was to identify methods of capturing and retaining machine or process specific knowledge so that it could be easily communicated to all.

The subproject created the NC online manuals website as a way to create an easily accessible database of knowledge. The website was formed early on and has been built up and expanding throughout the Rapid Response Small Machining project.

A Unigraphics users group was formed and meets regularly to present challenges $\mathrm{NC}$ analysts encounter and share solutions to department wide issues. This provides an open forum to proactively gain knowledge and be aware of potential pitfalls instead of being in a reactive, crisis situation that is counterproductive to the rapid response objective. Custom part templates are also being used to increase efficiency. Part templates increase the uniformity of our group programming methods making it exponentially easier for analysts to go from one program to another for troubleshooting, an issue regardless of who is the originating author. 
A result of this subproject will be an upgrade to Unigraphics NX 6. New revisions of software will lead to improvements in usability and function that simplify work and dramatically reduce turn around time.

NC program generation streamlining has been thoroughly examined many times in the past, not leaving a lot of room for improvement. However the Rapid Response funding has allowed the $\mathrm{NC}$ programming team to establish a few key areas readying them for transition into the sourcing future at the new KCP.

\section{Pallet System Study for Special Applications Machining}

KCP tested a Delphin pallet system from System 3R to determine if it would have the accuracy needed to support special applications machining while giving the flexibility and decreased setup time necessary to support an Agile machining area for the future.

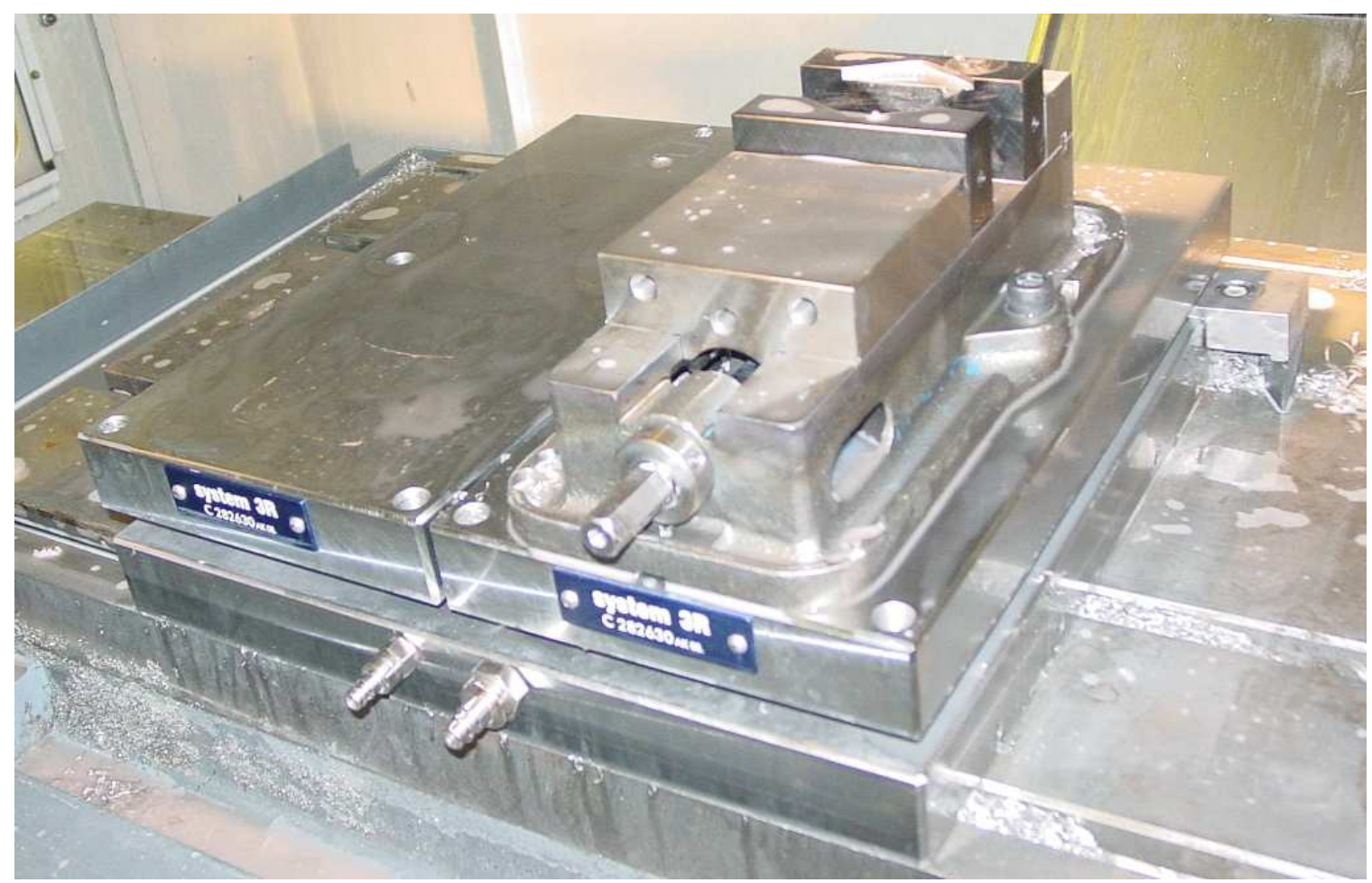

Figure 5: Delphin Pallet System from System 3R

KCP demonstrated that by using a pallet system, setup time can be reduced significantly (30 minutes vs. 4.5 hours) without a loss in accuracy. KCP also prepared for the future by purchasing a pallet system that increases the utilization and flexibility of mills in precision machining. Utilization is increased by reducing idle time of the spindle. Flexibility is increased by a reduction in setup time. This reduction makes it quicker and less expensive to stop and change jobs. For the intricate parts with small lot sizes that KCP specializes in, a large portion of the cost of the parts is setup and dialing in the first piece. The pallets minimize this cost by removing much of the manual labor from the setup. This change in process will better prepare precision machining to transform into an Agile special applications machining area in the new facility. 


\section{First Piece Inspection CMM}

This project encompassed the installation and implementation of an in-process CMM for operators to use on department products in FY07. A Brown \& Sharp CMM was used with Metrologic XG programming software for operation in the department as shown in the following figures. The majority of the programming actually took place off-line through the use of Silma XG. The flexibility of this software allows multiple engineers to simulate CMM programs at their desk before running the program on the machine. The CMM was relocated from another department annex into the department and transitioned to function on the smaller department product line. This sub-project was spun off as its own ADAPT project in FY08 and FY09.
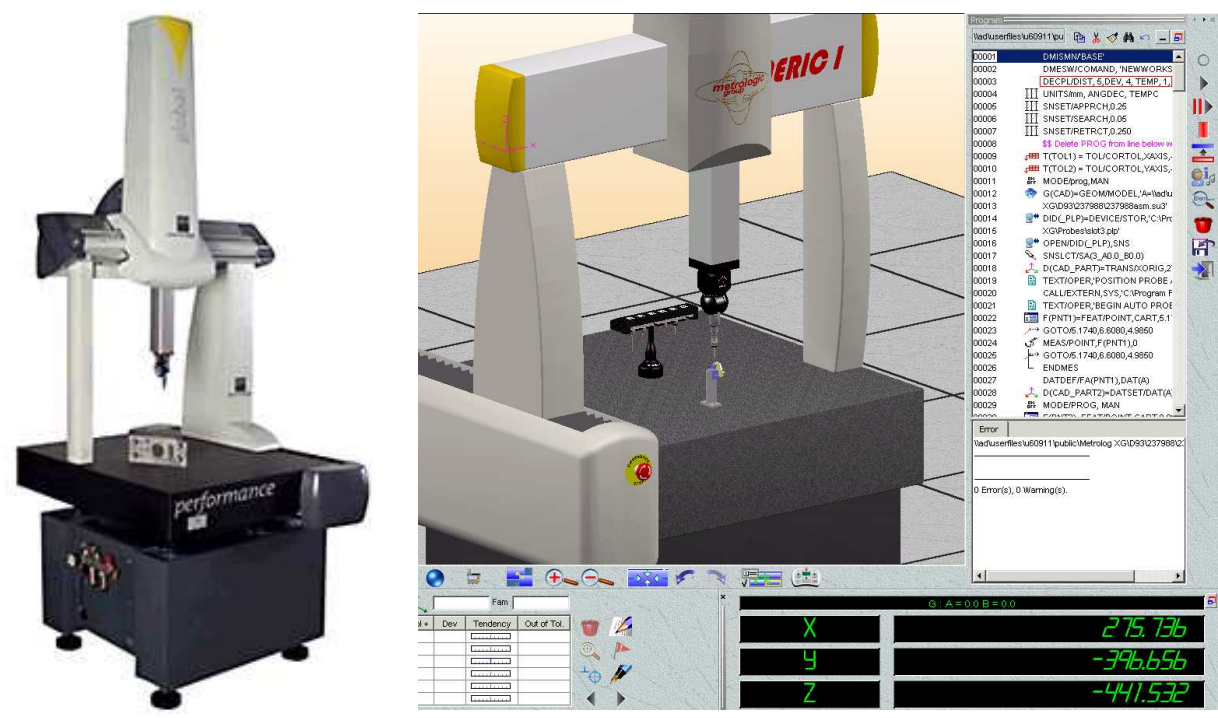

Figure 6: Actual Machine and Silma XG Off-line Programming Software

\section{Embedded Engineering}

This subproject was initiated by Fitzgerald as part of his aforementioned Agile Machining Processes Standardization project. The intent was to incorporate findings from Lean teams on having engineering desks reside on the shop floor. This would in theory reduce time necessary to make changes, promote interaction with shop floor team members, and create accessibility to salaried staff. The Hermle milling area and the Gildemeister cell were the best candidates to attempt this at first. The first step was to establish computing resources for the engineers at the work center locations. The shop floor work station PCs were upgraded to be able to run typical engineering and NC software. The engineers' schedules did not allow for a high priority effort on this project and the new plant plans were announced to begin planning for a move to a new building. It was then determined to limit time on this effort as the new building will drive this decision in the future. The benefit gained from this sub team was the ability for $\mathrm{NC}$ and engineering to begin using the work station machine for computing on the factory floor. 


\section{Conversational Programming}

This subproject evaluated the use of conversational programming in the MMT cell (Gildemeister). Some previous engineering efforts into this programming resulted in creation of a few basic programs for turning work. The same engineer was contacted to kick off the evaluation. The stub tubes were selected for a test part for this type of programming. The process engineer used the basic programs to write his own conversational program to machine the stub tubes in one operation. (Previous processing used 4 turning and milling operations). Parallel to this, the NC analyst affiliated with the MMT cell used the template type programming to create his own program to also process the part in the same one step operation. The results of the two programs were analyzed and the best methods selected for use. The conversational program had the advantage of ease of editing by the machinist during the prove-in process. However, this was not enough to warrant all the time, effort, and potential dangers of having the process engineer create the program (especially since it would not go through a post processor to check for bugs and crashes). The $\mathrm{NC}$ analyst had learned quite a bit from the team environment established in the MMT effort and his support, along with the template type programming, is the preferred method to use. Thus the conversational programming subproject was closed out. Some of the routines are still being used.

\section{$\underline{\text { Heat Exchanger Kellenberger Hydraulic System }}$}

The Kellenberger cylindrical grinder is the machine tool that is used when the greatest accuracy is required in the production of a round cylindrical surface. Parts are mounted in a rotating spindle and the table is moved back and forth along the centerline of the spindle and part while the outside surfaces of the part contact the rotating grinding wheel.

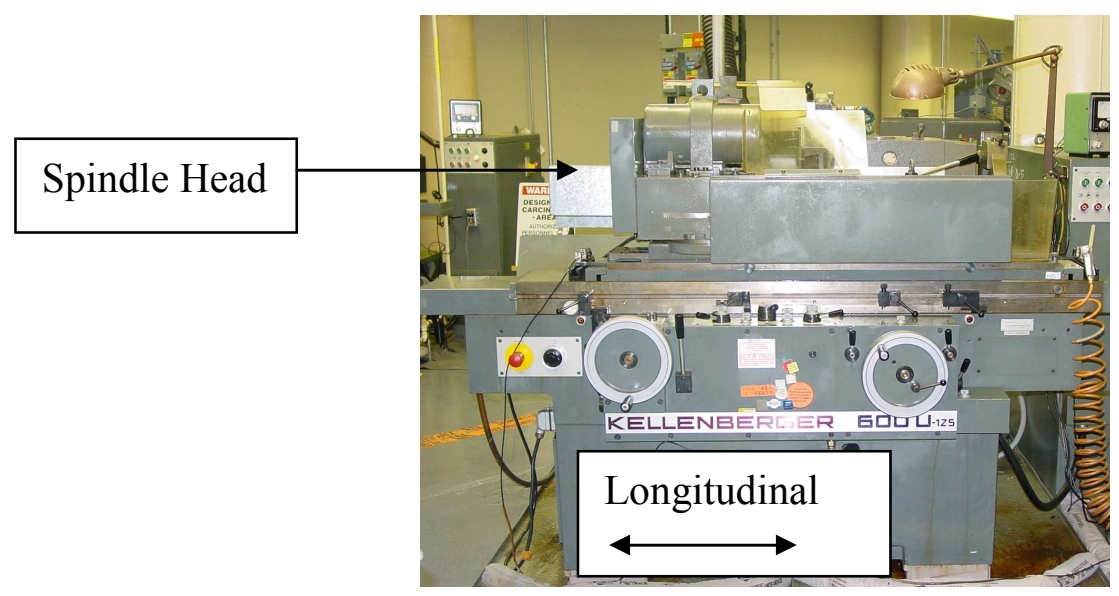

Figure 7: Kellenberger Cylindrical Grinder

Within the department the Kellenberger grinder is used to produce the final diameters of precision pistons. The longitudinal table drive and the transverse grinding head drive are hydraulic. The hydraulic reservoir is approximately 15 gallons and is a stand alone unit. The pump produces more flow than both the longitudinal and transverse drive can utilize and the system utilizes a hydraulic relief to return flow to the tank. The hydraulic lines go into the frame of the machine tool and run to the hydraulic drives. According to the machine prints the hoses 
are supported in the webs of the machine frame. The return hydraulic oil from the drives is returned to this reservoir with hoses also installed within the frame webs.



Figure 8: Supply and Return Lines Entering Machine Frame

The heated oil from the drives is returned in the frame under the moving table and the lines heat the table. Previous studies have shown that the hydraulic system is the heating source for the machine. In trying to maintain tolerances below 0.0002 inches this heating is causing a problem. During the day it is not unusual for temperatures to build up 35 to 45 degrees F. The Kellenberger design assumed that the cutting oil would remove part of the heat generated by the hydraulic system. The sump on this reservoir is 48 gallons and it remains within 5 degrees during the normal shift. The cutting oil flows when grinding while the hydraulic pumps runs all the time the machine tool is running.

Samples were ground at the same settings at 30 minute intervals. Part growth at finished dimensions was 0.0008 inch. Temperature of the return oil increased 28 degrees during this run of parts. This increase in hydraulic oil temperature caused the bed of the machine to heat. Also the heating rate is not constant. The machine tool is left on during breaks. During this period a majority of the flow of the hydraulic system is over the relief valve and that allows the temperature to build within the hydraulic reservoir. Starting with this machine at $72^{\circ} \mathrm{F}$, the hydraulic oil heated to $87^{\circ} \mathrm{F}$ during the first thirty minutes of operation. To counteract this initial heating the grinder is warmed up 60 minutes before the first part is ground. To counteract this growth the machinist is constantly adjusting the cross slide setting in order to produce consistent parts within the tolerance band.

With a tolerance band of 0.0002 on the diameter the machinist is hard pressed to maintain part tolerance. Only a skilled grinder with years of running these machines has the experience to generate parts to within this tolerance band. This experienced machinist will still produce a scrap part because of temperature changes.

In order to reduce the temperature rise during the day a $6000 \mathrm{BTU} / \mathrm{Hr}$ Fan Cooled-Liquid to Air Heat Exchanger made with copper tubing was purchased from McMaster-Carr. The unit is approximately 12 in x 12 in x 5 in and is very quiet. This unit can be used in the return line and mounted on the top of the hydraulic reservoir. The unit has a pressure rating of $150 \mathrm{psi}$, a 
working temperature rating of $400^{\circ} \mathrm{F}$. Actual running pressure is less than 20 psi. Heat is directed away from the machine tool, operator, and reservoir.

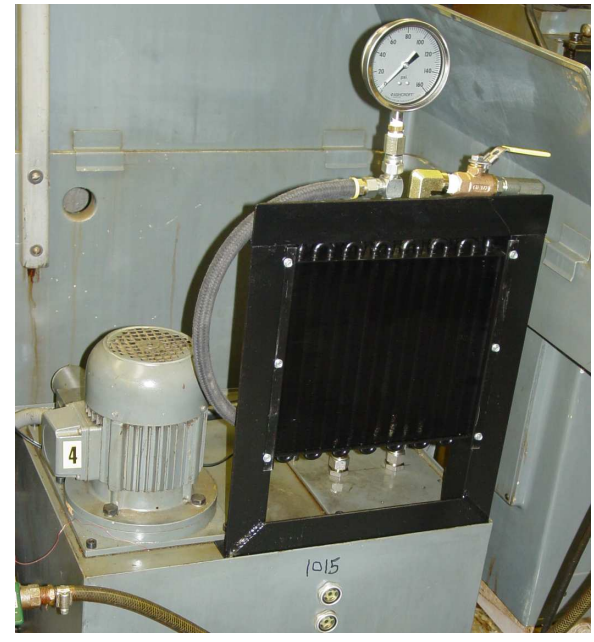

Figure 9: Installation of Heat Exchanger

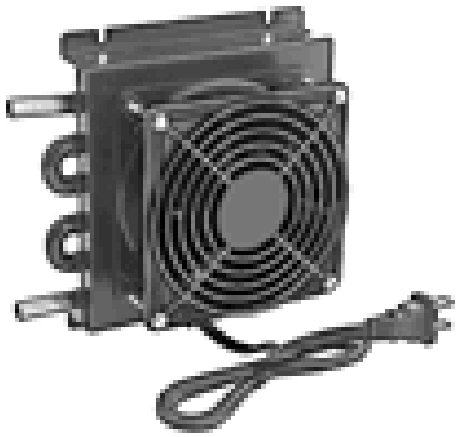

Figure 10: Reverse Side of Heat Exchanger

The installation of the heat exchanger together with running this drive, except when loading and unloading parts, reduces the hydraulic heat load. This slows the temperature change of the hydraulic oil and act as a temperature dampener on the hydraulic system. Temperature increases during the day were within 15 degrees after the initial heating during warm-up. Sizes variation stabilized within one hour instead of two hours before the heat exchanger was installed. If the drives are not running, the heat exchanger is not effective because the pressure relief is build into the hydraulic tank.

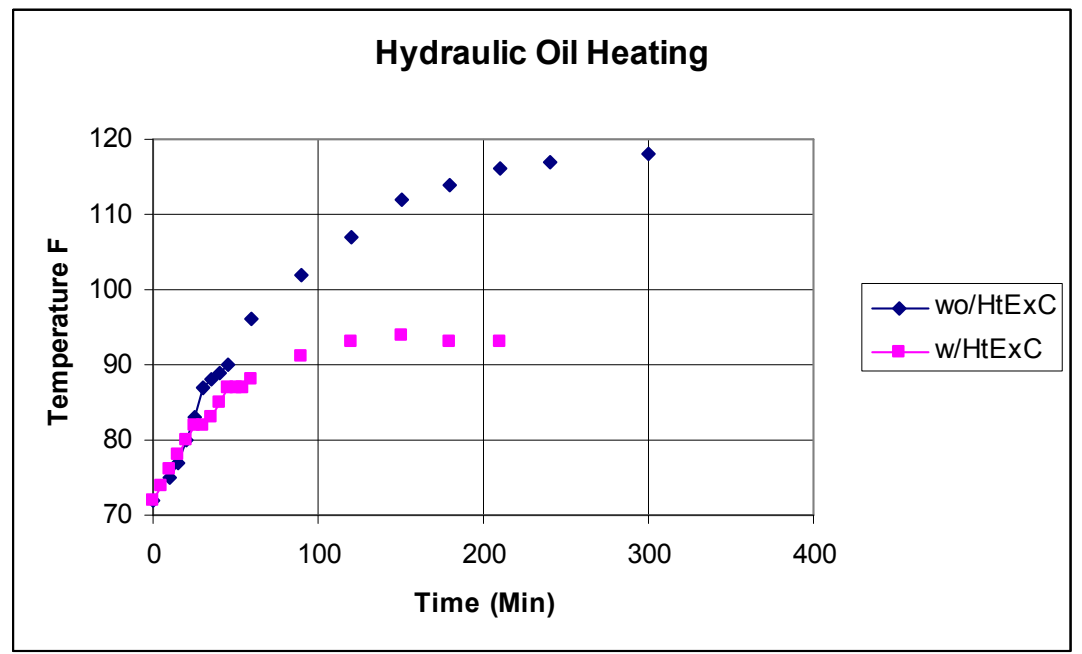

Figure 11: Hydraulic Oil Heating 


\section{Chiller/Metalworking Fluid Systems on Precision Lathes}

Flood coolant is one of the methods used to remove heat generated in the metal removal process. In the case of larger parts (greater than 5 inches diameter) the influence of the metal working fluid (MWF) can be significant in controlling part contours variation because of temperature changes.

To cut a spherical contour on a five inch diameter can take 10 minutes or more. The chip generated absorbs most of the heat. The chip falls into the chip tray and the MWF flow across the chip absorbing part of the heat. The MWF also absorbs heat from the work piece as well as removing heat in the cutting zone. It is not unusual for the fluid in the sump to heat 20 to 30 degrees during the day. When combining a 30 degree temperature rise, a 5 inch diameter, and the coefficient of thermal expansion for the work piece material, it has a major effect in controlling a contour to within 0.0020 inches tolerance.

A 6000 BTU chiller was installed on the process and machining evaluation laboratory's American lathe that is used for performing machinability tests. The sump was filled with a chlorinated mineral oil with a high flash point. During a three hour span when many machinability runs were made, the temperature rise of the oil was $22^{\circ} \mathrm{F}$. The chiller has its own temperature controller and was set to maintain the MWF temperature to within a 4 degree span. The chiller was able to maintain the MWF within this temperature span.

The chiller runs at a constant flow. The refrigeration system kicks in when the set temperature drops one degree below the set point. The oil is chilled and returned at the midpoint of the sump. This allows the warmer oil generated in the cutting process to be mixed with chilled oil before being pulled into the chiller intake at the end of the lathe bed. The system has enough capacity to maintain the MWF temperature during machinability testing.

During subsequent testing after the chiller was installed, the 4 degree temperature span for the oil entering the lathe MWF delivery pump was never exceeded. The chiller will be more effective when water-based metalworking fluid is used. It has a much greater capacity to remove heat due to the evaporative cooling effect of the water that is not gained by using cutting oil.

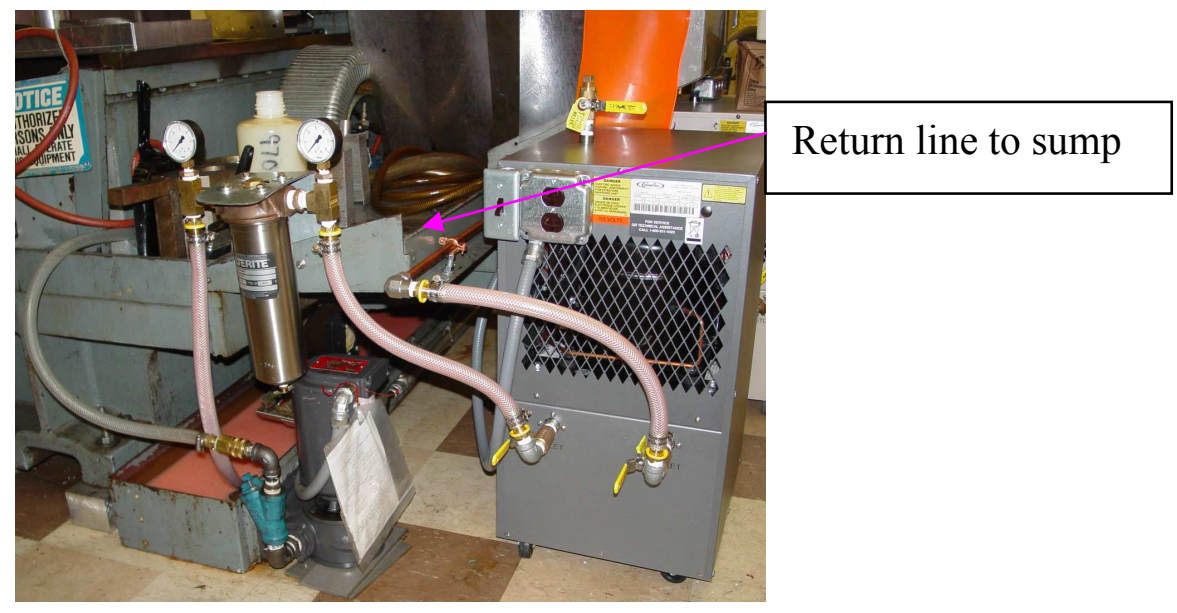

Figure 12: Chiller Installed on American Lathe 


\section{$\underline{\text { Implementing Lean in SAM }}$}

Three small projects were undertaken to implement additional Lean practices in preparation for the transition to the Special Applications Machining (SAM) department.

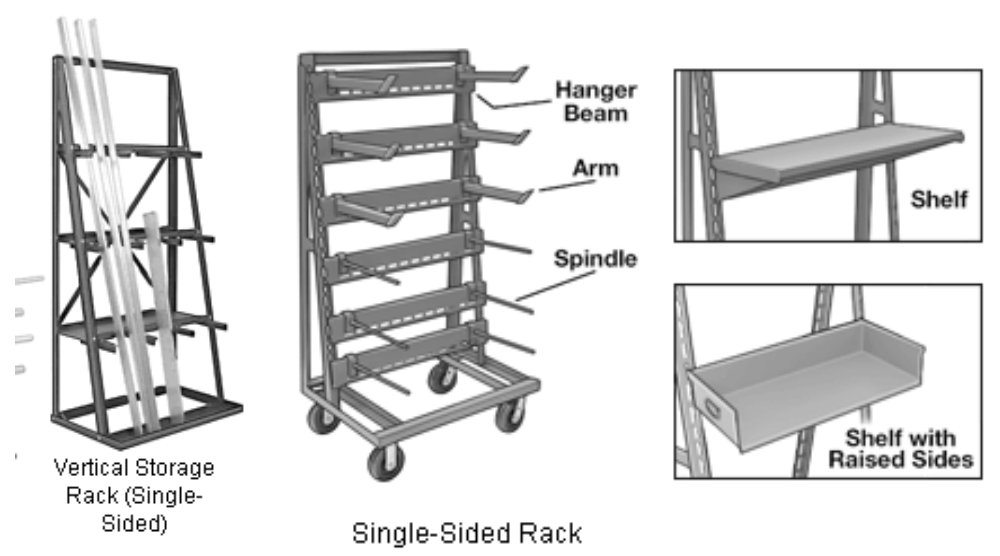

Figure 13: Material Racks

The first project was for the movement of materials and bar storage. A vertical storage rack was purchased and will be set up in the tool crib to store small to medium size bar. A vertical storage rack will take up less floor space than a horizontal rack. A second single-sided mobile horizontal bar storage rack was obtained and stored behind the Star Screw Machines. This rack can be moved to the bar feeder machines and will facilitate loading jobs that use the bar feeder. Another of these mobile racks was obtained to deliver material from the receiving area to the machine tools. Both racks were obtained with both arms and shelves so that flat and round bar in small pieces and long lengths can be delivered.

The mobile setup carts have proved so successful for the Hermle 5 Axis Mill, Star, and Gildemeister cells that additional carts were obtained. All dedicated machine tooling for a specific machine tool is maintained in the cart with mounting hardware and hand tools. Also standard perishable cutting tools are maintained in the cart. In this way the machinist or model maker will have what is needed to setup the job in the cart, thus eliminating a lot of time spent collecting items needed for a setup. The cost reduction submitted for the Hermle cell detailed the saving for the setup carts and was audited in 2006. There will be one cart for each cell in the new plant layout. In the case of the large lathe and 4-axis mill cell, a second cart was obtained for the cell. Based on two shift operation with both production and development jobs being setup within the cells, these carts will save time in setting machine tools 


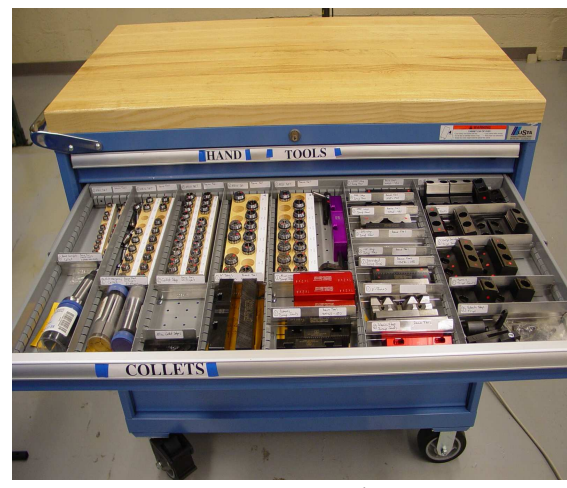

Hermle

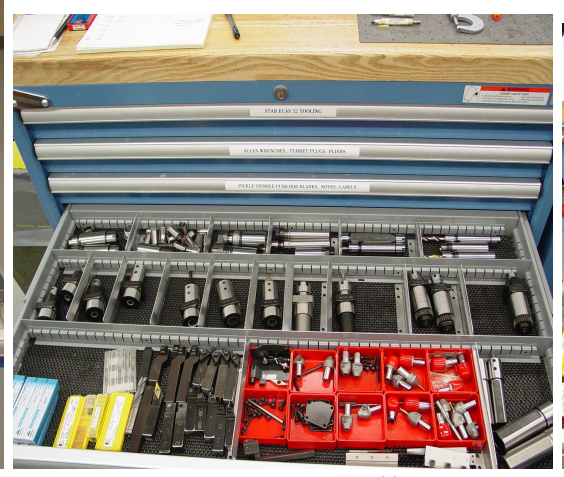

$20 \mathrm{~mm}$ Star Cell

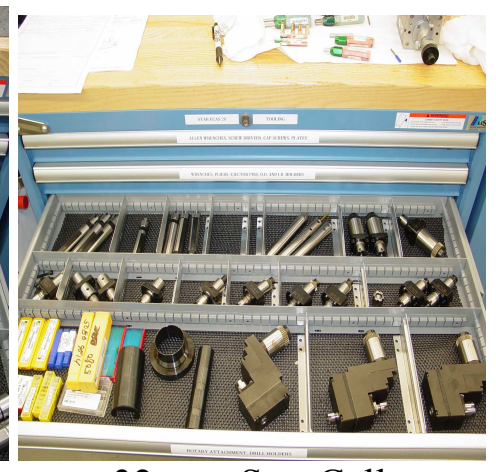

$32 \mathrm{~mm}$ Star Cell

Figure 14: Lean Cell Setup Carts

\section{High Speed Machining}

This subproject resurrected the high speed head attachment on the White Sundstrand milling machine in the department through the following activities:

- Performed tests and improved confidence in use of the head.

- Discovered and fixed electrical and mechanical problems before use on specific product: Replaced many refrigerant and coolant hoses and recharged the refrigerant reservoir.

- Determined the best end mill configuration, cutter path, starting point cutting conditions (ready for real work where the values will probably be somewhat different). Developed Unigraphics techniques for cutter path, speeds, feeds, etc. obtaining acceptable surface finish.

- Trained machinists in the use of the high speed head.

- Configured and tested Vericut (virtual machining software application) which had never been used on a high speed machine.

\section{Reprocess the Fireset Housing to the Department}

This sub team reprocessed the fireset housing from a 4-axis horizontal spindle machining center in the old Flexible Manufacturing System (FMS) area to the 5-axis vertical spindle center (Hermle) in the department. The new process was able to provide cost effective modification of existing hard tooling (tooling funded by the program). NC analysts generated new NC machining programs for fifth axis and new probing routines. 


\section{References}

${ }^{1}$ Greg Thompson, Virtual Optical Comparator (Final Report) UNCLASSIFIED. FM\&T:

KCP-613-8517, October 2008.

${ }^{2}$ Mike Clinesmith, Non Contact Laser Measurement (Final Report) UNCLASSIFIED. FM\&T: KCP-613-8535, November 2008 
Appendices 


\section{Appendix}

\section{A. Medium Mill-Turn Cell}

\section{Activities, Milestones, and Achievements}

\section{General Description}

Many parts in production in the department had existing processes set up to use multiple machining operations to produce parts. The medium mill-turn cell subproject focused on reprocessing many of those parts to utilize a Gildemeister CTX320 mill-turn machine, in order to reduce the number of operations, setups, standard hours, and flow time. The parts that were reprocessed to the mill-turn cell required mostly turning operations and some milling operations. Most of the parts either had existing processes on the Hardinge Superslant and/or CNC Chucker lathes in the department, or would have been processed on those machines if the mill-turn cell had not been implemented.

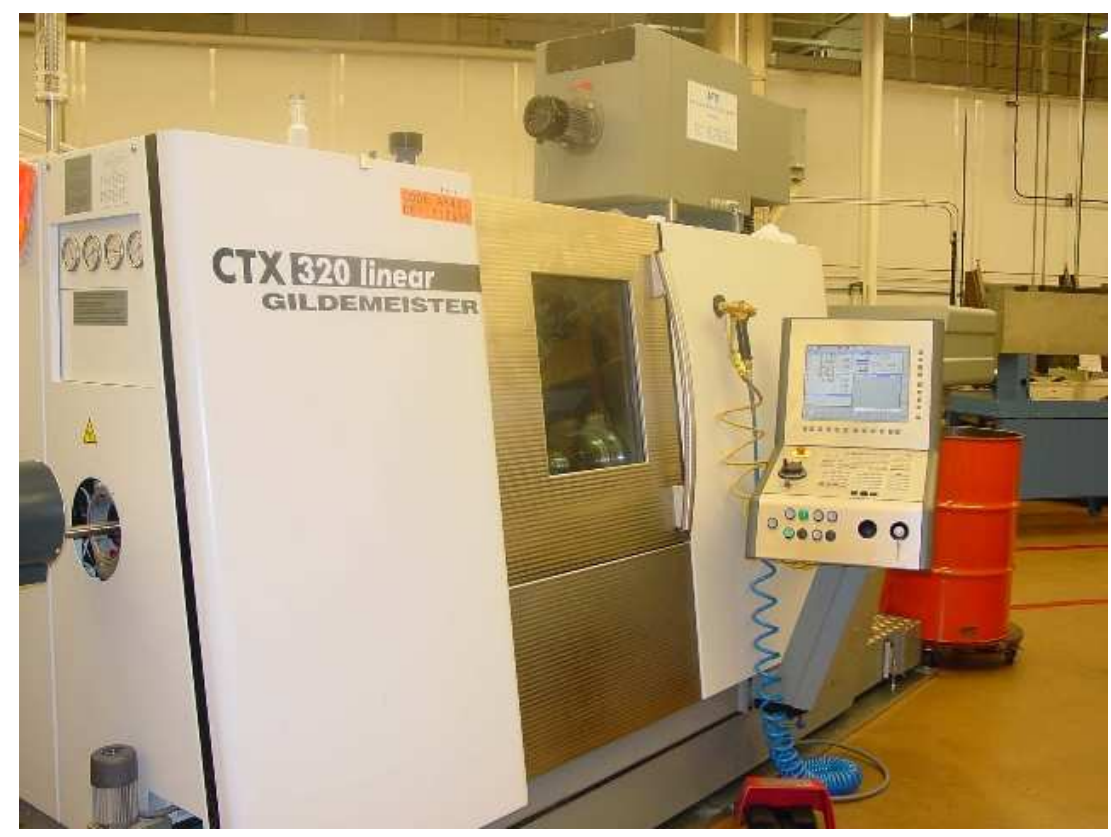

External view of one of the Gildemeister CTX 320 mill-turn machines.

In addition to reprocessing parts, the MMT cell incorporated many changes in the ways that work is performed beginning with the methods of designing the manufacturing processes and obtaining the required tooling and programming support, through proving in and improving the process during manufacturing, and then coordinating with final inspection to verify part quality earlier in the process, when improvements can produce greater results. 


\section{Improved Communication}

The natural team for the medium mill-turn cell consisted of two process engineers, an industrial engineer, two numerical control analysts, three machinists, and one OTM. The team met on a regular basis to discuss various issues within the cell such as production schedules and priorities, technical challenges, lessons learned, and ideas to improve production efficiency and quality. The increased amount of communication between team members during the design phases of processing helped to identify and eliminate some problems early on, when changes are easier to make and defects can be avoided.

The team also made use of a log book at each machine to document machine errors and how to resolve them, as well as many other bits of helpful information about setting up and running the machines. This book is used as a quick reference when troubleshooting machine errors or proving in a new process or numerical control program.

\section{Reprocessing}

A total of 20 separate part numbers were reprocessed to the Gildemeister mill-turn machine in the department. In most cases, this action replaced multiple NC machining operations, as well as some manual operations, with a single NC machining operation. This reduced the number and length of setups, reduced total cycle time, and increased throughput. The following process map shows a simplified example of this.

\section{Medium Mill-Turn Cell Example Process Map}

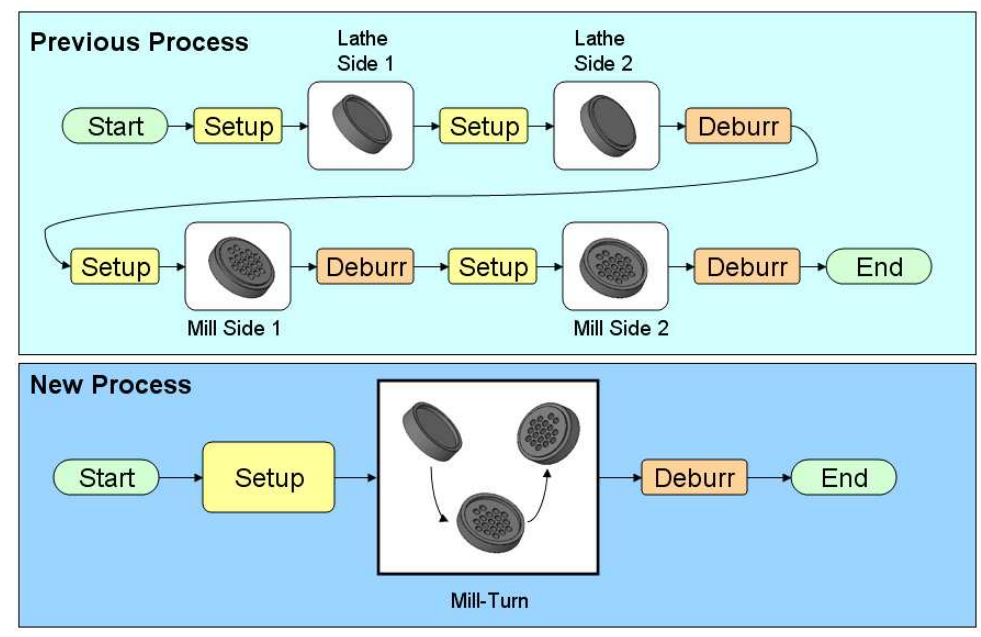

\section{$\underline{\text { Standard Tools }}$}

The team developed a standard setup consisting of several tooling blocks, cutting tools, and inserts, and designated those as the default tools to have set up in the machine (see tables in the appendix to this report which is part of Appendix A). This standard setup, along with other 
information about the machines, was posted on an internal website to make it easily accessible to anyone working in the cell.

When the process engineer creates a new process, these tools are used whenever possible. This reduces the amount of time it takes to switch production from one part number to another, since most of the tools commonly used are already set up in the machine.

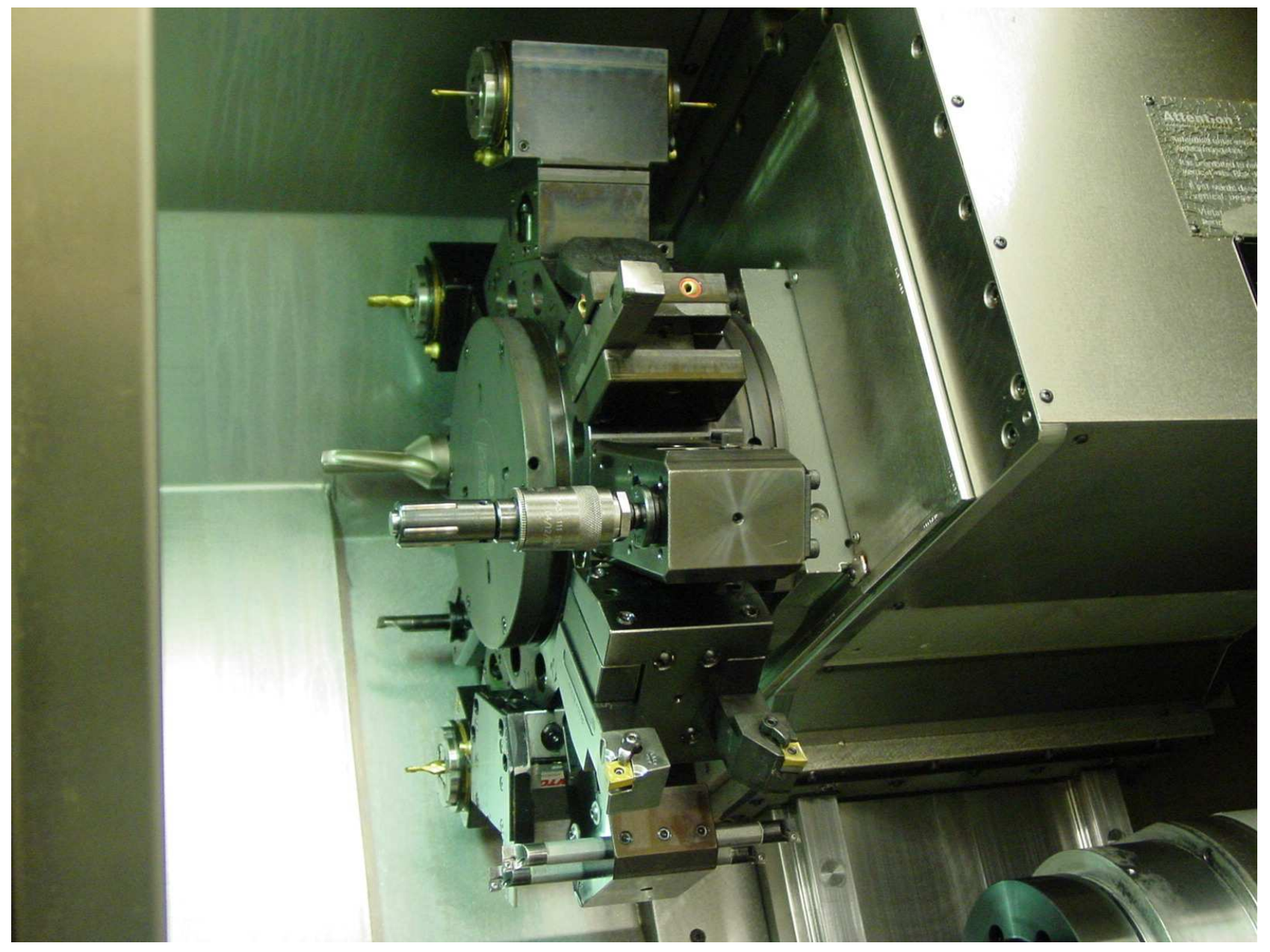

Turret in the Gildemeister mill-turn machine, with standard tools set up.

\section{Reorganized Work Areas}

The work areas around each machine were reorganized so that turret blocks, tool holders, cutting inserts, and other tooling are kept in standard areas. Each machine has the same standard complement of tooling, and the tool cabinets have been segmented and labeled for storing standard as well as alternate tools and inserts. Having the tools organized in this fashion makes it simpler to find tooling when needed, and also helps the operator know when they need to replenish a particular insert or tool before depletion. 


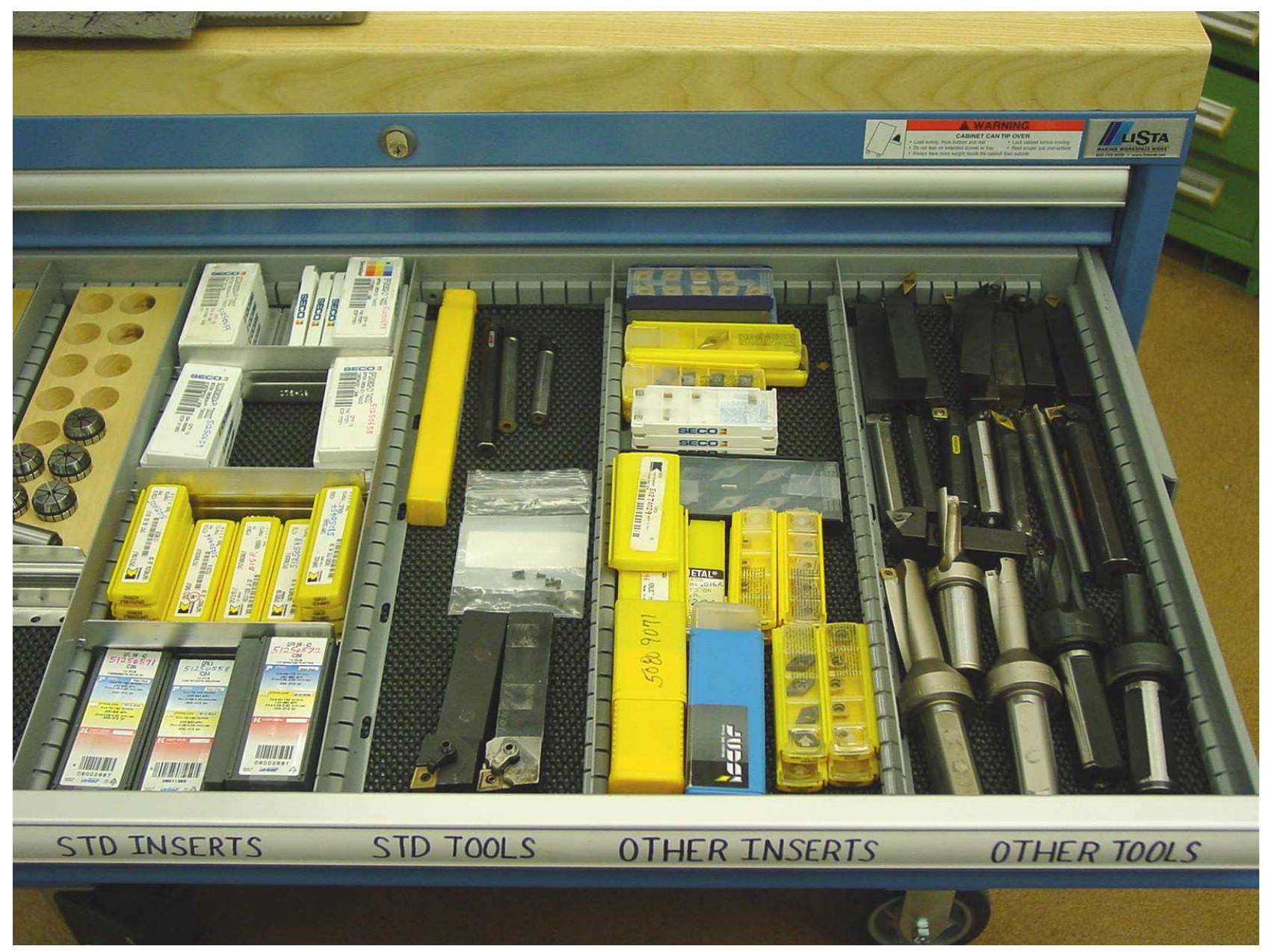

Example of reorganized work area for standard and other tooling storage. 


\section{Machine Alignment Verification}

Misalignment between spindles, turrets, and tools can cause many quality problems and added costs in a manufacturing process, especially in relatively complex machining operations such as a mill-turn machine which has the potential to combine several machining operations into one. Misalignment can occur in many situations such as the spindle chuck or collet being changed, a tool block being changed on the turret, or the machine is moved. Spindle/turret misalignment is also difficult to detect and diagnose as the root cause of some defects, since there are many other variables that contribute to the overall quality and productivity of the machining process.
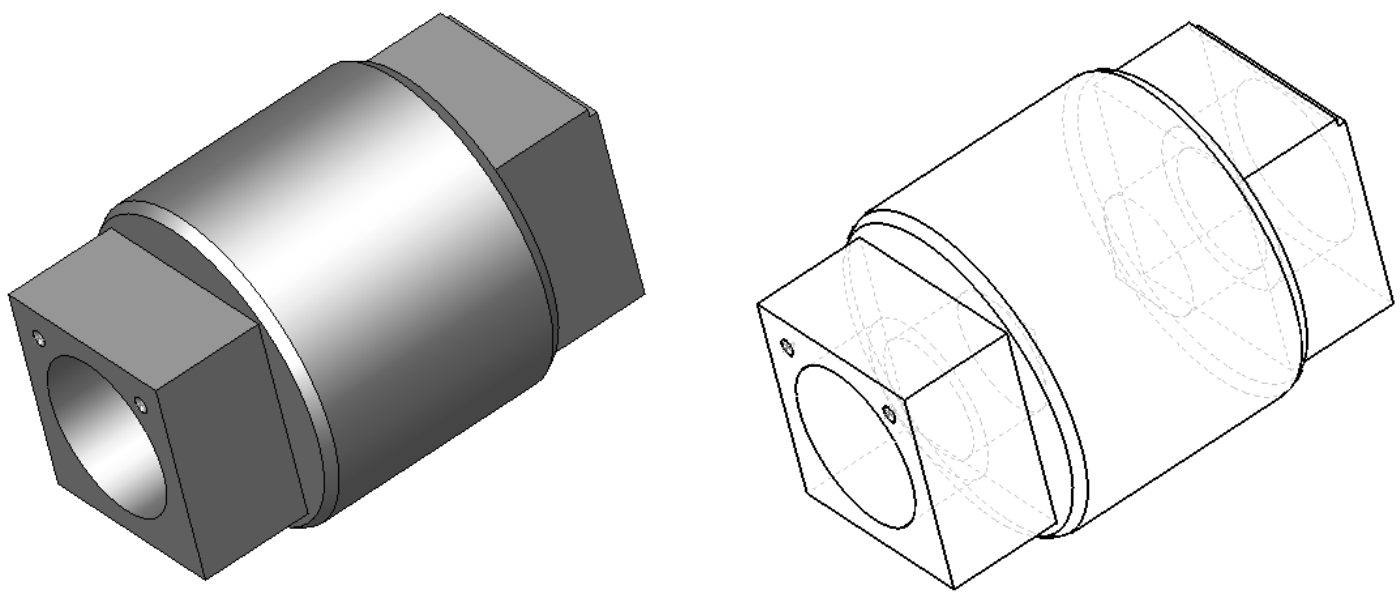

Models of a test part designed to check machine accuracy and repeatability.

The MMT cell team completed the design and prove in of a test part that can be used to check the accuracy and repeatability of the Gildemeister mill-turn machine. Groups of these parts will be machined before and after the machines are moved, and inspection data from each group will be compared as part of the overall verification of machine accuracy and proper alignment. This test can also be run when troubleshooting the setup of a new machining process, to eliminate misalignment as a potential cause of errors while avoiding the extra costs and downtime that would be incurred if the machine were taken out of service to do a full maintenance alignment procedure. This alternative to the formal laser realignment process will save an estimated $\$ 13,000$ each year.

\section{Cost Savings}

Baseline standard hours for setup and production operations were calculated based on the operations that would be replaced or eliminated by the mill-turn operation. Part quantities and number of setups were determined by lot sizes and part schedules in a 12-month period following reprocessing. Savings were based on standard hour reductions for several parts, as well as an increase in the yield for the 1Axx cylinder. The use of standard tooling for most of the cutting tools used on each part further reduced setup time by eliminating the need to replace and reset those tools when changing production to a new part. The use of parametric programming 
techniques also reduced the time spent by engineers and programmers to create, edit, and support the numerical control programs used to machine parts.

Detailed comparisons of the previous processes vs. the new processes are included in the appendix.

Standard hour reductions on parts produced in the cell resulted in a savings of approximately $\$ 22,000$ in FY06, \$13,000 in FY07, and an estimated \$12,000 in FY08.

The forecast yield for the 1Axx cylinder was raised in FY07 from $80 \%$ to $90 \%$ based on parts produced since implementation of the mill-turn cell. This resulted in a savings of approximately $\$ 7,000$ due to a reduction in projected scrap as well as the number of parts that would need to be started in the next 12 months in order to meet the needs of the next level assembly. 


\section{Appendix}

\section{Contents:}

1. Standard tool list for Gildemeister mill-turn machine, front side of turret.

2. Standard tool list for Gildemeister mill-turn machine, back side of turret.

3. Screenshot of the KCP internal website for the Gildemeister mill-turn machines.

4. Photo taken during machining of a 1 Axx cylinder.

5. Photo showing the turret and the front and rear spindle inside the Gildemeister.

6. Design of test part for checking machine alignment, accuracy, and repeatability.

7. Calculations of standard hour savings in FY06.

8. Calculations of standard hour savings in FY07.

\section{STANDARD TOOLS FRONT}

\begin{tabular}{|c|c|c|c|c|c|c|c|c|c|}
\hline $\begin{array}{c}\text { T. } \\
\text { POSN }\end{array}$ & OFFSET & HOLDER & $\begin{array}{c}\text { INSERT } \\
\text { HOLDER }\end{array}$ & $\begin{array}{l}\text { CUTTING } \\
\text { TOOL }\end{array}$ & $\begin{array}{c}\text { TOOL } \\
\text { SLZERAD }\end{array}$ & $\begin{array}{c}\text { MAX DOC } \\
\text { MIN BORE } \\
\text { TPI }\end{array}$ & $\begin{array}{l}\text { TOOL } \\
\text { PROJ. }\end{array}$ & HAND & COMMENTS \\
\hline 1 & 1 & 1" Square & 50808401 & 51250454 & $.031 R$ & $.250 \mathrm{DOC}$ & 1.3 & L & $\begin{array}{l}\text { Rough } \\
\text { Face/Tum }\end{array}$ \\
\hline 2 & 2 & l" Round & - & - & - & - & - & - & OPEN \\
\hline 3 & 3 & 3/4" Square & - & - & - & - & - & - & OPEN \\
\hline 4 & 4 & PROBE & 48005375 & $1 \mathrm{~mm}$ & - & - & - & - & Probe \\
\hline 5 & 5 & $\begin{array}{l}\text { DRWN clt } \\
\text { double }\end{array}$ & CLT & $\begin{array}{c}\text { TC0259750- } \\
005\end{array}$ & $.125 \mathrm{D}$ & $.625 \mathrm{DOC}$ & .75 & - & Spot Drill \\
\hline 6 & 6 & $\begin{array}{c}\text { DRVN clt } \\
\text { double }\end{array}$ & CLT & - & - & - & - & - & OPEN \\
\hline 7 & 7 & 3/4" Square & - & - & - & - & - & - & OPEN \\
\hline 8 & 8 & 3/4" Round & Not Open & Not Open & $\begin{array}{l}\text { Not } \\
\text { Open }\end{array}$ & Not Open & \begin{tabular}{|l|} 
Not \\
Open
\end{tabular} & \begin{tabular}{|c} 
Not \\
Open
\end{tabular} & Not Open \\
\hline 9 & 9 & OPEN & - & - & - & - & - & - & OPEN \\
\hline 10 & 10 & OPEN & - & - & - & - & - & - & OPEN \\
\hline 11 & 11 & Cutoff holder & 50809617 & 51250571 & $.118 \mathrm{~W}$ & $1.5 \mathrm{DOC}$ & - & L & Cutoff \\
\hline 12 & 12 & $1 / 2^{\prime \prime}(2)$ hole & 50808212 & 51250406 & $.008 \mathrm{R}$ & $\begin{array}{c}.030 \mathrm{DOC}, \\
.593 \mathrm{D}\end{array}$ & 1.3 & $\mathrm{R}$ & $\begin{array}{c}\text { Finish } \\
\text { Face/Turn - } \\
\text { Bore }\end{array}$ \\
\hline 12 & 13 & $1 / 2^{\prime \prime}(2)$ hole & $\begin{array}{r}50808212 \\
\text { STA }\end{array}$ & $\begin{array}{c}51250548 \\
\text { TDART TO }\end{array}$ & $\begin{array}{c}.004 R \\
\text { OL.S RA }\end{array}$ & $\begin{array}{c}.030 \mathrm{DOC}, \\
\mathbf{K}^{593 \mathrm{D}}\end{array}$ & 1.3 & $\mathrm{R}$ & $\begin{array}{c}\text { Finish } \\
\text { Face/Turn - } \\
\text { Bore }\end{array}$ \\
\hline
\end{tabular}

Standard tools list for Gildemeister mill-turn machine, front side of turret. 


\begin{tabular}{|c|c|c|c|c|c|c|c|c|c|}
\hline T.POSN & OFFSET & HOLDER & $\begin{array}{l}\text { INSERT } \\
\text { HOLDER }\end{array}$ & $\begin{array}{l}\text { CUTTING } \\
\text { TOOL }\end{array}$ & $\begin{array}{c}\text { TOOL } \\
\text { SIZERARAD }\end{array}$ & $\begin{array}{c}\text { MAX DOC } \\
\text { MIN BORE } \\
\text { TPI }\end{array}$ & $\begin{array}{l}\text { TOOL } \\
\text { PROJ. }\end{array}$ & HAND & COMMENTS \\
\hline 1 & 21 & 1" Square & 50808879 & 51250406 & $.008 \mathrm{R}$ & $.030 \mathrm{DOC}$ & 1.3 & $\mathrm{R}$ & $\begin{array}{l}\text { Rough } \\
\text { Face/Turn }\end{array}$ \\
\hline 2 & 22 & 1" Round & - & - & - & - & - & - & OPEN \\
\hline 3 & 23 & 3/4" Square & - & - & - & - & - & - & OPEN \\
\hline 4 & $\begin{array}{l}\text { Not } \\
\text { Open }\end{array}$ & Not Open & Not Open & Not Open & $\begin{array}{l}\text { Not } \\
\text { Open }\end{array}$ & Not Open & $\begin{array}{l}\text { Not } \\
\text { Open }\end{array}$ & $\begin{array}{l}\text { Not } \\
\text { Open }\end{array}$ & Not Open \\
\hline 5 & 25 & DRVN COLLET & - & $\begin{array}{c}\text { TC0259750- } \\
005\end{array}$ & $.125 \mathrm{D}$ & $.625 \mathrm{DOC}$ & .75 & - & Spot Drill \\
\hline 6 & 26 & $\begin{array}{c}\text { DRVN clt } \\
\text { double }\end{array}$ & CLT & - & - & - & - & - & OPEN \\
\hline 7 & 27 & 3/4" Square & - & - & - & - & - & - & OPEN \\
\hline 8 & $\begin{array}{l}\text { Not } \\
\text { Open }\end{array}$ & Not Open & Not Open & Not Open & $\begin{array}{l}\text { Not } \\
\text { Open }\end{array}$ & Not Open & $\begin{array}{l}\text { Not } \\
\text { Open }\end{array}$ & $\begin{array}{l}\text { Not } \\
\text { Open }\end{array}$ & Not Open \\
\hline 9 & 29 & OPEN & - & - & - & - & - & - & OPEN \\
\hline 10 & 30 & OPEN & - & - & - & - & - & - & OPEN \\
\hline 11 & - & - & - & - & - & - & - & - & NOT OPEN \\
\hline 12 & 14 & $1 / 2 "$ (2) hole & 50808215 & 51250406 & $.008 \mathrm{R}$ & $\begin{array}{c}.030 \mathrm{DOC} \\
.593 \mathrm{D}\end{array}$ & 1.3 & L & $\begin{array}{c}\text { Finish } \\
\text { Face/Turn - } \\
\text { Bore }\end{array}$ \\
\hline 12 & 15 & $1 / 2 "(2)$ hole & 50808215 & 51250548 & $.004 \mathrm{R}$ & $\begin{array}{c}.030 \mathrm{DOC}, \\
593 \mathrm{D}\end{array}$ & 1.3 & L & $\begin{array}{c}\text { Finish } \\
\text { Face/Tum - } \\
\text { Bore }\end{array}$ \\
\hline
\end{tabular}

Standard tools list for Gildemeister mill-turn machine, back side of turret. 


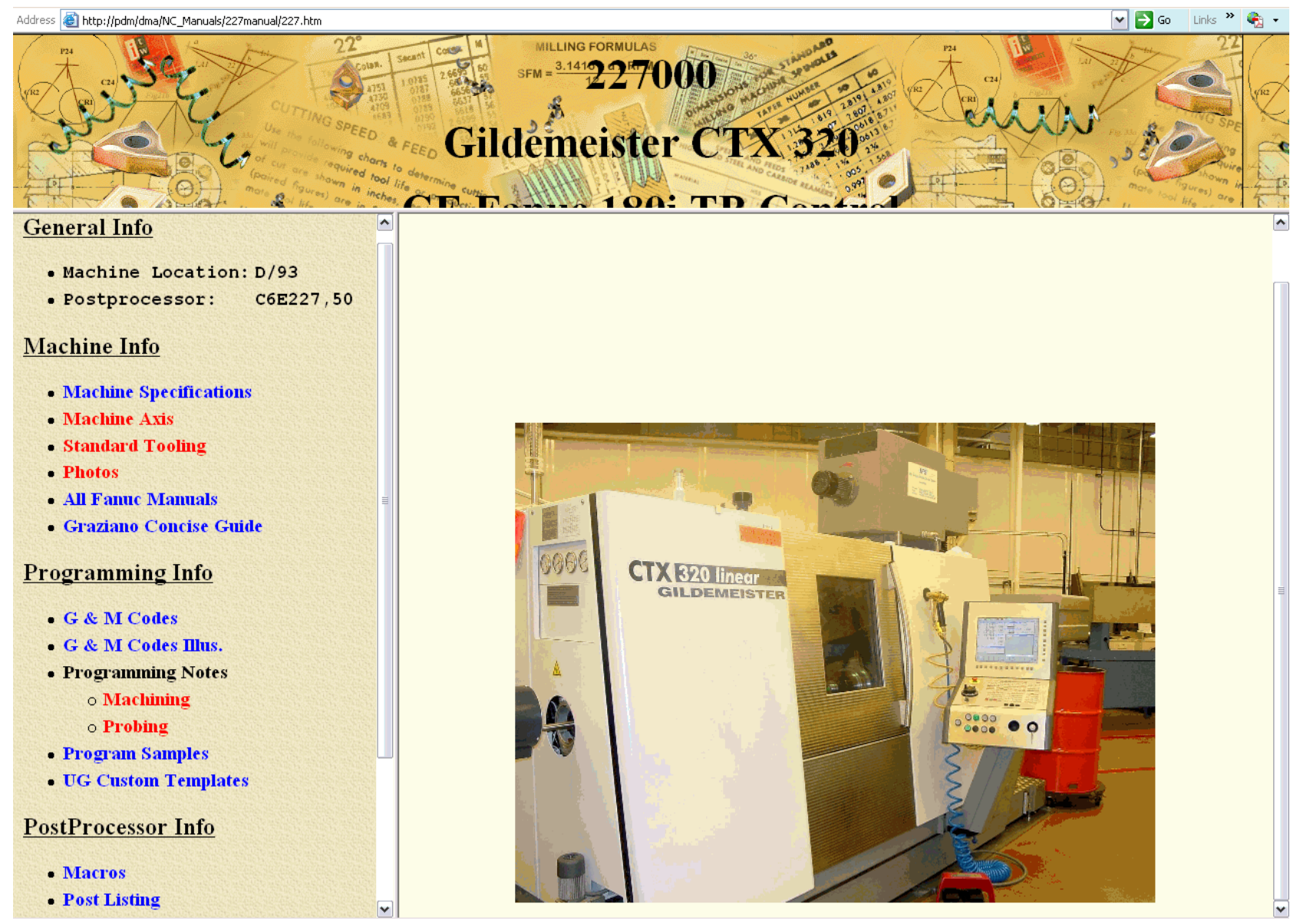

Screenshot of the KCP internal website for the Gildemeister mill-turn machines. 




Machining a cylinder. 


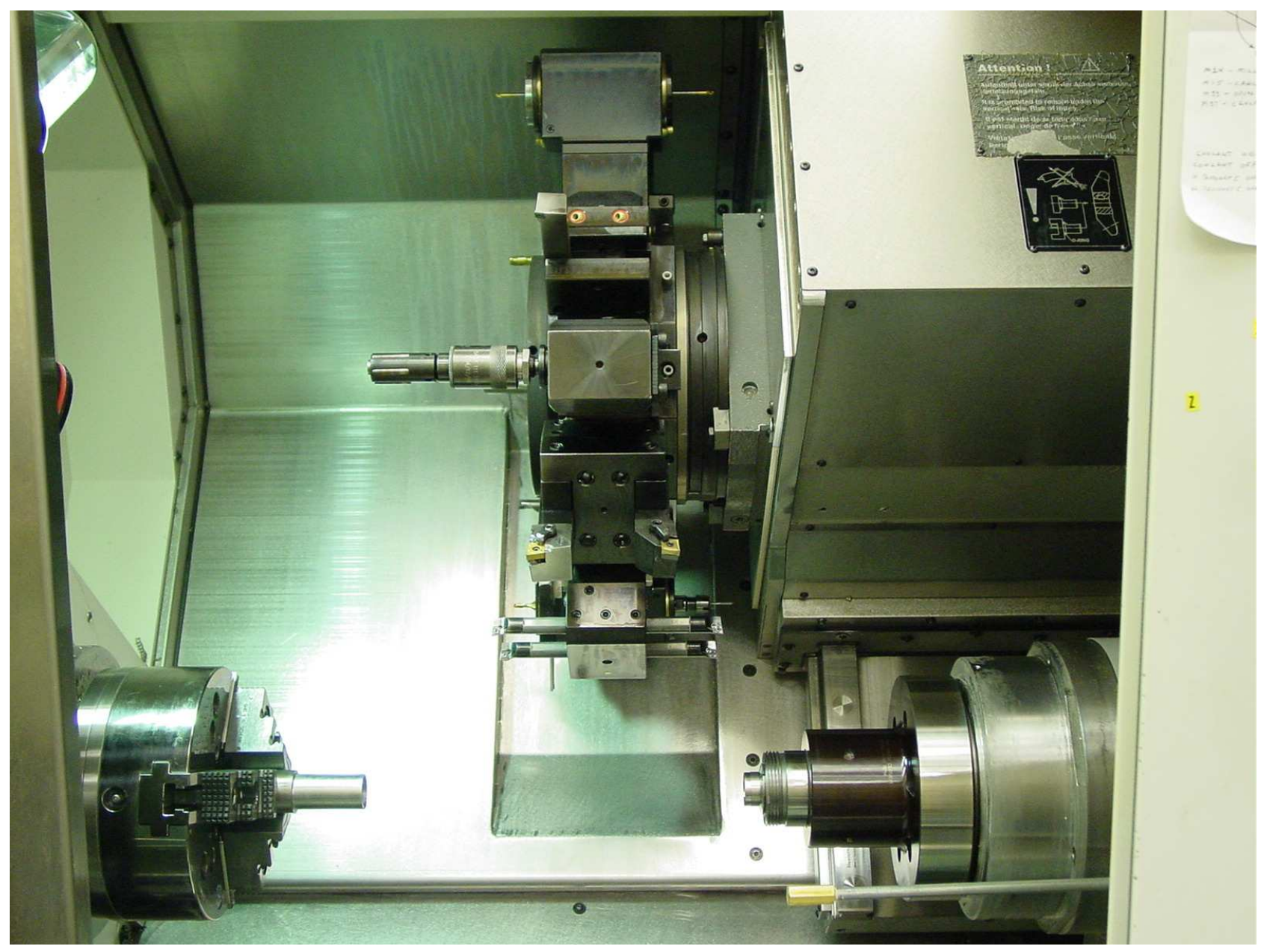

Turret and front and rear spindles inside the Gildemeister mill-turn machine. 


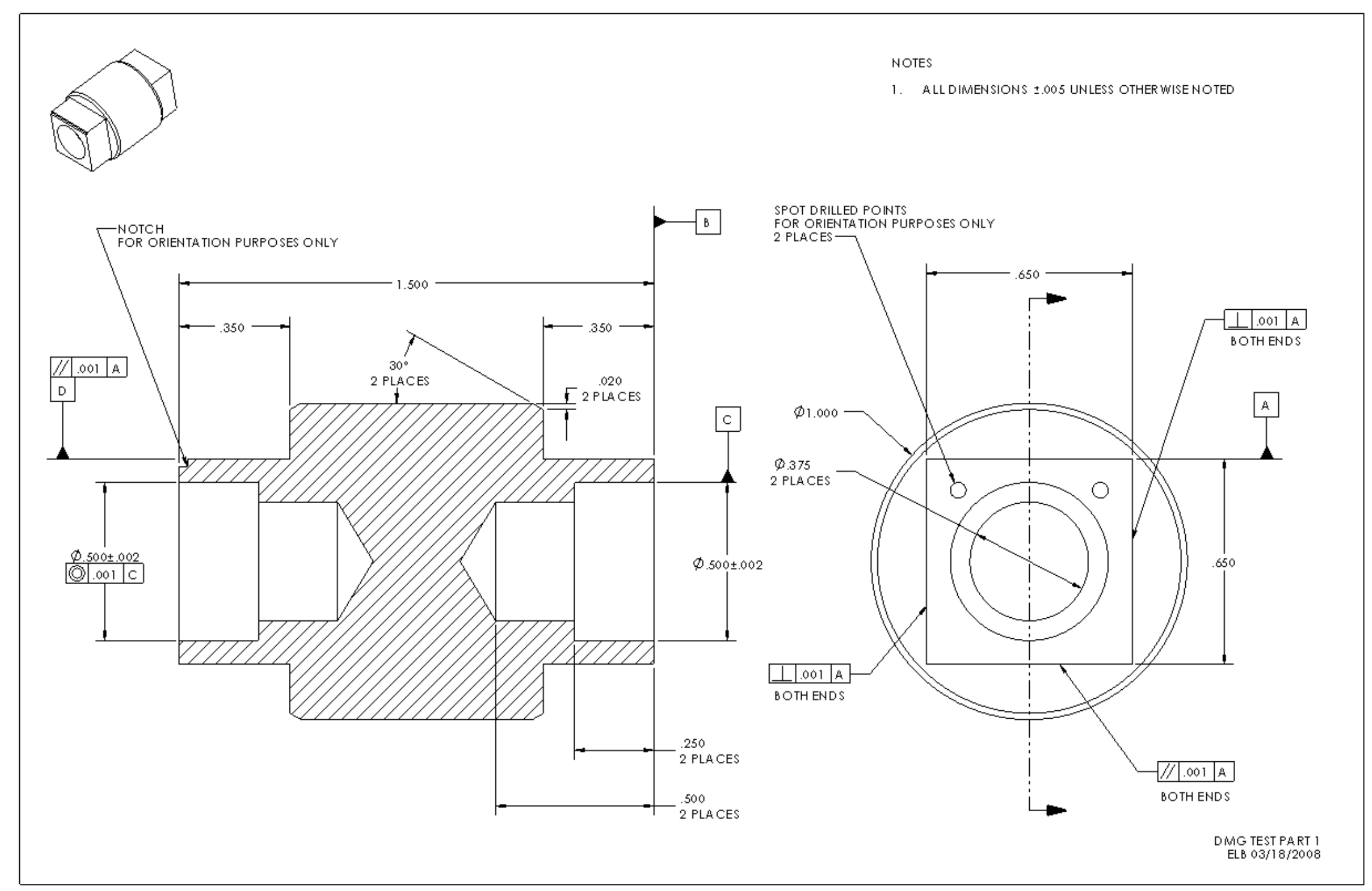

Design of test part for checking machine alignment, accuracy, and repeatability. 
Medium Mill-Turn Cell

Standard Hour Cost Savings FY06

\begin{tabular}{|c|c|c|c|c|c|c|c|c|c|c|c|c|}
\hline & Ori & ginal Proce & & MMT & T Cell Proce & ess & & & & & & \\
\hline Item Number & Operation & $\begin{array}{c}\text { Setup } \\
\text { Standard } \\
\text { Hours }\end{array}$ & $\begin{array}{c}\text { Standard } \\
\text { Hours }\end{array}$ & Operation & $\begin{array}{l}\text { Setup } \\
\text { Standard } \\
\text { Hours }\end{array}$ & $\begin{array}{c}\text { Standard } \\
\text { Hours }\end{array}$ & $\begin{array}{c}\text { Setup } \\
\text { Standard } \\
\text { Hour } \\
\text { Savings }\end{array}$ & $\begin{array}{c}\text { Standard } \\
\text { Hour } \\
\text { Savings } \\
\text { Per Part }\end{array}$ & $\begin{array}{l}\text { Parts } \\
\text { Count }\end{array}$ & $\begin{array}{l}\text { Lot } \\
\text { Size }\end{array}$ & $\begin{array}{c}\text { Total } \\
\text { Standard } \\
\text { Hour } \\
\text { Savings }\end{array}$ & $\begin{array}{c}\text { Total } \\
\text { Dollar } \\
\text { Savings }\end{array}$ \\
\hline
\end{tabular}

\begin{tabular}{|c|c|c|c|c|c|c|c|c|c|c|c|c|}
\hline \multirow{7}{*}{ Plug, Cap, Output } & 20 & & 0.025 & & & & & & & & & \\
\hline & 80 & 2.710 & & 89 & 2.146 & & & & & & & \\
\hline & 90 & & 0.171 & 90 & & 0.093 & & & & & & \\
\hline & 95 & 2.500 & & 99 & 2.500 & & & & & & & \\
\hline & 97 & & 0.190 & 100 & & 0.190 & & & & & & \\
\hline & 100 & 1.000 & & & & & & & & & & \\
\hline & 110 & & 0.081 & & & & & & & & & \\
\hline Total & & 6.210 & 0.467 & & 4.646 & 0.283 & 1.564 & 0.184 & 1267 & 100 & 252.5 & $\$ 9,414$ \\
\hline
\end{tabular}

\begin{tabular}{|c|c|c|c|c|c|c|c|c|c|c|c|c|}
\hline & 9 & 3.000 & & 9 & 3.000 & & & & & & & \\
\hline \multirow[t]{3}{*}{ Cylinder } & 10 & 0.600 & & 10 & 0.025 & & & & & & & \\
\hline & 910 & 2.051 & & 409 & 2.051 & & & & & & & \\
\hline & 1010 & & 0.708 & 410 & & 0.566 & & & & & & \\
\hline Total & & 5.651 & 0.708 & & 5.076 & 0.566 & 0.575 & 0.142 & 783 & 20 & 133.7 & $\$ 4,984$ \\
\hline
\end{tabular}

Shouldered Shaft

\begin{tabular}{llllllllllll}
19 & 3.890 & & 709 & 4.204 & & & & & & & \\
20 & & 1.938 & 710 & & 0.459 & & & & & \\
29 & 2.359 & & & & & & & & & \\
30 & & 0.407 & & & & & & & & \\
35 & & 0.174 & & & & & & & & \\
39 & 2.562 & & & & & & & & & \\
40 & 8.811 & $\mathbf{2 . 8 1 9}$ & & 4.204 & 0.459 & 4.607 & 2.360 & 46 & $\mathbf{2 0}$ & 119.1 & $\$ 4,442$ \\
\hline
\end{tabular}

\begin{tabular}{|c|c|c|c|c|c|c|c|c|c|c|c|c|}
\hline $\begin{array}{l}\text { Positive Indicator Plug } \\
\text { Total }\end{array}$ & $\begin{array}{c}9 \\
10\end{array}$ & $\begin{array}{l}4.000 \\
4.000\end{array}$ & $\begin{array}{l}0.250 \\
0.250\end{array}$ & $\begin{array}{c}9 \\
10\end{array}$ & $\begin{array}{l}3.200 \\
3.200\end{array}$ & $\begin{array}{l}0.200 \\
0.200\end{array}$ & 0.800 & 0.050 & 141 & 20 & 12.7 & $\$ 473$ \\
\hline $\begin{array}{l}\text { Cover } \\
\text { Total }\end{array}$ & $\begin{array}{c}9 \\
10\end{array}$ & $\begin{array}{l}4.386 \\
4.386\end{array}$ & $\begin{array}{l}0.346 \\
0.346\end{array}$ & $\begin{array}{c}9 \\
10\end{array}$ & $\begin{array}{l}2.910 \\
2.910\end{array}$ & $\begin{array}{l}0.094 \\
0.094\end{array}$ & 1.476 & 0.252 & 179 & 20 & 58.3 & $\$ 2,172$ \\
\hline
\end{tabular}


Medium Mill-Turn Cell

Standard Hour Cost Savings FY07

\begin{tabular}{|c|c|c|c|c|c|c|c|c|c|c|c|c|}
\hline Item Number & Operation & $\begin{array}{l}\text { ginal Proce } \\
\text { Setup } \\
\text { Standard } \\
\text { Hours }\end{array}$ & $\begin{array}{c}\text { Standard } \\
\text { Hours }\end{array}$ & Operation & $\begin{array}{l}\text { Cell Proce } \\
\text { Setup } \\
\text { Standard } \\
\text { Hours }\end{array}$ & $\begin{array}{c}\text { Standard } \\
\text { Hours }\end{array}$ & $\begin{array}{l}\text { Setup } \\
\text { Standard } \\
\text { Hour } \\
\text { Savings }\end{array}$ & $\begin{array}{l}\text { Standard } \\
\text { Hour } \\
\text { Savings } \\
\text { Per Part }\end{array}$ & $\begin{array}{l}\text { Parts } \\
\text { Count }\end{array}$ & $\begin{array}{l}\text { Lot } \\
\text { Size }\end{array}$ & $\begin{array}{l}\text { Total } \\
\text { Standard } \\
\text { Hour } \\
\text { Savings }\end{array}$ & $\begin{array}{c}\text { Total } \\
\text { Dollar } \\
\text { Savings }\end{array}$ \\
\hline & 29 & 3.144 & & 29 & 4.000 & & & & & & & \\
\hline \multirow{8}{*}{ Web, 18 Pin } & 30 & & 0.159 & 30 & & 0.300 & & & & & & \\
\hline & 50 & & 0.089 & & & & & & & & & \\
\hline & 69 & 5.628 & & & & & & & & & & \\
\hline & 70 & & 0.207 & & & & & & & & & \\
\hline & 90 & & 0.199 & & & & & & & & & \\
\hline & 109 & 2.892 & & & & & & & & & & \\
\hline & 110 & & 0.103 & & & & & & & & & \\
\hline & 130 & & 0.175 & & & & & & & & & \\
\hline \multirow[t]{2}{*}{ Total } & & 14.549 & 0.931 & & 4.000 & 0.507 & 10.549 & 0.425 & 225 & 75 & 135.2 & $\$ 5,209$ \\
\hline & 29 & 2.960 & & 39 & 4.077 & & & & & & & \\
\hline \multirow[t]{5}{*}{ Retainer, 18 Pin } & 30 & & 0.513 & 40 & & 0.332 & & & & & & \\
\hline & 50 & & 0.121 & 90 & & 0.164 & & & & & & \\
\hline & 69 & 2.960 & & & & & & & & & & \\
\hline & 70 & & 0.245 & & & & & & & & & \\
\hline & 90 & & 0.125 & & & & & & & & & \\
\hline \multirow[t]{2}{*}{ Total } & & 5.920 & 1.003 & & 4.077 & 0.495 & 1.843 & 0.507 & 180 & 60 & 104.8 & $\$ 4,038$ \\
\hline & 29 & 2.960 & & 729 & 5.280 & & & & & & & \\
\hline \multirow[t]{5}{*}{ Retainer, 22 Pin } & 30 & & 0.193 & 730 & & 0.244 & & & & & & \\
\hline & 50 & & 0.121 & & & & & & & & & \\
\hline & 69 & 2.960 & & & & & & & & & & \\
\hline & 70 & & 0.197 & & & & & & & & & \\
\hline & 90 & & 0.215 & & & & & & & & & \\
\hline Total & & 5.920 & 0.725 & & 5.280 & 0.244 & 0.640 & 0.481 & 195 & 40 & 97.0 & $\$ 3,737$ \\
\hline
\end{tabular}

Grand Total

$\$ 12,983$ 


\section{Appendix B}

\section{B. Report for Rapid Response Project for the STAR Mill-Turn Cell}

\section{Scope of Work}

This project was initiated to reduce the part cycle time on the two STAR Swiss Mill-Turn machines by reducing the setup times and the actual machining times. Listed in the accomplishments section of the report are the specific actions performed in an attempt to accomplish this task. Some of the performed work created savings through cycle time reduction, while other work created cost savings through the reduction of scrap. Some work did not create any measurable cost savings, but it made the machinist's job easier.

Cost savings associated with this project are as follows:

A total cycle time reduction of approximately 105 days on several STAR parts emerged through some of the stated work in the accomplishments section of this report. This equates to approximately $\$ 30,000$ worth of savings in the next year.

In addition, scrap reduction savings totaling approximately $\$ 129,000$ emerged on several parts due to some of the other work performed on this project.

\section{Accomplishments}

\section{Addition of Brass Setup Stock for All Parts Run on the Star Machines}

In the past, the STAR machines were setup using the same bar stock material called out on the bill of material that the actual parts were to be made of. This wasted a lot of bar stock because it usually took quite a few parts to get all of the dimensions within tolerance so acceptable parts could be made.

To reduce the waste of this material, the bill of material was changed to add brass bar stock to be used to setup the STAR Swiss mill-turn machines. This allows the machinist to setup the machine and run good parts without wasting very much material, and also allows the parts to be run dry so that the tool paths can be seen by the operator. Using the brass to setup with also greatly reduces tool wear during the setup machining process, and thus a reduction in tool changes during this time. Therefore, brass setup stock increases the efficiency of the operator in setting up the part on the machine and reduces actual part material waste.

\section{Additional Installation of Lighting on Both STAR Machines}

The operators were having difficulty seeing the part as it was being machined, and the tooling during tooling changes due to the lack of adequate lighting within the machine. Four lights were 
purchased for the purpose of improving this situation. Two lights were mounted on each of the two STAR machines; one was mounted on the inside of each machine, while the other was mounted on the outside of each machine. This improved the situation considerably.

\section{Creation of Standard Ejector Pin Blanks for Each STAR Machine}

Ejector pins are required by both STAR machines in the pickup collet to push or "eject" the part out of the collet when the collet is opened after the part is complete. Without them, the part would just sit in the collet and have to be removed by hand.

Every part requires a different ejector pin due to the differences in the geometry from part to part, both in diameter and length. In the past, if a new ejector pin was required, it was obtained in one of two ways. Either the STAR operator had to stop setting up the machine and make a new pin from bar stock on the manual lathe or the engineer put in a work order to have a blank ejector pin made by TEM. When it was completed and delivered to the department, the operator finished it to size on the manual lathe to work with that particular part.

In an effort to free up machinist time and reduce the lead time for ejector pin blanks, a project tool order (PTO) was input into the system to design and make 25 standard ejector pin blanks for each STAR machine. They were made out of brass and can be easily machined on a manual lathe to be used with any new part. When quantities run low, they can be reordered with the tool number that was assigned to them during the design process.

\section{Bench Center Setup to Verify Axis Concentricity Using Grinding Centers}

Bench centers were purchased to verify the parts with grinding centers that were made on the STAR machines. This was because at one time there was a very high instance of concentricity problems with STAR parts and it was not being discovered until after most of the machining and heat treating was completed and the parts were at the grinding operation.

The bench centers allowed the STAR machinist to check the concentricity of the grinding centers to the outside diameter of the part at the machine. This allows the operator to make adjustments to the machine if necessary to correct the problem or get the machine realigned, if necessary. A large quantity of scrap parts and time was saved by using the bench centers for concentricity verification.

\section{Indexing Fixture to Verify Axis Concentricity Without Grinding Centers}

Concentricity problems were also occurring on parts that required grinding but did not contain grinding center holes. This problem was not being found until the parts were at the grinding operation. In an effort to reduce the occurrence of the problem and discover it as early as possible, an ER25 collet indexing fixture was purchased and used in the cell to chuck up and rotate parts to verify the concentricity between their outer diameters with an indicator. This significantly reduced 
the quantity of this type of ground part being scrapped due to concentricity problems at the grinding operation.

\section{Verification Sheet Implementation to Incorporate Inspection Instructions}

In the past, verification instructions were placed at the very end of the process narrative for each operation to verify the machining process dimensions. Sometimes the instructions were confusing, hard to find, on several different pages of the routing, and/or were different than those in the inspection instructions. Therefore, verification sheets were implemented for all parts made on the STAR machines. These verification sheets put the following verification information for each part in a tabular form on one sheet of paper: verification method and equipment required by the current inspection instruction to verify each dimension and the frequency at which each dimension is required to be verified. This is a much easier format for the operator to follow and much truer verification process which equates to better quality parts going to inspection.

\section{Co-Ax Indicator Setup to Check Tool Runout}

Co-ax indicators were purchased for both STAR machines. These are used to indicate the stock relative to the guide bushing, and the picked up part relative to the pick-up collet. This method is used as an indication of the machine alignment. If the indicated runout is too great, then machine realignment is required. Machine misalignment isn't generally recognized until it is too late to save the machined parts, so it must be looked for during the setup of the machining operation.

\section{Flat Nose/Shortened Pickup Collets on Both STAR Machines}

Pickup collet nose length has caused problems in the past in some cases. Pickup collets were initially purchased with the maximum possible nose length. However, it was found that in many cases, this causes problems like part misalignment and part runout. The cause of these problems is from the elongated portion of the collet jaws getting permanently sprung open unequally during use. It was also determined that if the collet nose is cut down in length, or purchased with the nose length as short as possible, this problem was greatly reduced. Therefore, the standard pickup collet nose length has been decreased, and the initially purchased long nose pickup collets have had their length reduced as required to produce acceptable product.

\section{Flats on Bore Tool Insert Holders}

Bore tools generally have flats ground on the shank to allow the tools to slide into the bore tool holders where a set screw is tightened against the flat to align the cutting edge of the tool with the coordinate system of the machine and the axis of the bar stock. If there are no alignment flats on the shank of the bore tool, then the cutting edge has to be manually aligned to the machine by marking it with an indicator. This was the case with the some of the bore tools used on the STARs. Since they did not have the alignment flats, they had to be indicated in. 
To alleviate this problem, bore tools without flats were taken to cutter grinding to have a flat ground on the shank that was parallel to the cutting surface on the tool tip. The tool drawings were then changed to incorporate this into the design of the tool. Alignment flats are a big time saver to the machinist when setting up and replacing bore tools since they do not need to be indicated in.

\section{Relocation of Roughing Tools to Turret 3 to Clear Chips More Readily}

Initially, the standard tooling setup for the smaller STAR was arranged so that all of the turning tools were in turret 1 with the cutting edges facing up. After running several different part numbers, it was found that if a large quantity of material was removed with one of those tools, in particular, the face and turn tool, then the large chips wadded up on the tool itself. To cure this condition, the tool which removes the most material is now placed in turret 3 in one of the lower three turning tool positions. Turret 3 tools are upside down and lower on the machine which allows the chip to fall into the chip conveyor more readily.

\section{Square Shank Bore Tool Holders for Ecas-32t}

Small bore tools on the larger STAR have caused rigidity problems on some of the smaller parts in the past. This is due to the fact that the bore tools are so short and small in diameter, generally the bar stock diameter is relatively small, and the configuration of the machine setup does not help either.

The designed machine setup for bore tools is the bore tool being mounted in the appropriate size shank bore sleeve, which is mounted in the round shank tool holder in the machine turret. The round shank tool holder is constructed in such a way that there is a rather large ( $\sim 6$ inches) offset away from the guide bushing, which is where the problem arises. This large offset means that the short bore tool has to be extended out of the sleeve as far as possible, and the sleeve has to be extended out of the round shank tool holder in the turret as far as possible to be able to remove material from the bar stock, or vice versa, the bar stock has to be extended out to reach the tool. Either way, it is not a rigid setup, particularly when dealing with a small bar stock diameter.

To create a more rigid small/short bore tool setup on the machine, square shank bore tool holders were designed and built. This allows the smaller shank/short bore tools to be mounted in a square shank tool holder which contains very little offset away from the guide bushing. Therefore, the cutting tip of the bore tool is directly adjacent to the guide bushing with the tool holder directly behind it, which provides for a very rigid setup.

\section{Add Plug Gage to Routings to Set Pickup Collet to Size and for Indicating Purposes}

As an aid in setting up the STAR machines more quickly, plug gages are used to set the size and pressure of the pickup collet. Of course, the plug gage size required for this setup is exactly the same as the part diameter that is chucked on when picking the part up. In addition, the plug gage chucked in the pickup collet is used to indicate the pickup spindle alignment when checked with 
the co-ax indicator. This is particularly useful for pinpointing concentricity problems when they occur.

The size of the chucking diameter is called out on the tool set sheets and the process illustrations, but the actual plug gage required to do this was added to the requirements list of the routing operation since it is a requirement for the machinist to complete the part setup and alignment check. 


\section{Appendix C}

\section{NC Process Improvements in the Cell}

The intent of this subproject is to analyze the business practices of the NC programming department, identify, and implement opportunities for improvement. Some businesses practices are inefficient and can cause lengthy turnaround times for program requests as well as being costly on machine prove in time.

There are seven NC analysts who maintain approximately fifty-one different post processors and support approximately 70 machine tools.

With the wide variety of tools and applications used plant wide it is difficult for individual analysts to be proficient in all applications of every process. Each tends to become somewhat specialized which limits the flexibility of the department. A major goal of this subproject was to identify methods of capturing and retaining machine or process

specific knowledge so that it could be easily communicated to all analysts. This led to the creation of the NC Online Manuals website. The website has been built and expanded throughout the Rapid Response Small Machining project in order to create an easily accessible database of knowledge.

The following photographs detail some of the important information that has been centralized.

\section{PROCESS FLOW FOR NC PROGRAMS}






This sidebar to a specific machine contains

programming notes, electronic manuals, machine diagrams, machine photographs, and links to custom templates needed to program.

\section{Machine Info}

- Standards

- Specifications

- Axis

- Tooling

- Tool Numbers

- Holders

- Standard Tools

- Photos

- Programming Manual

\section{Programming Info}

- G \& M Codes

- Diagrams

- Spindles

- Axis

- Channels

- Programming Notes

- Program Samples

- UG Custom Templates

- UG Seed Part

\section{$\underline{\text { PostProcessor Info }}$}

- Post Request

- Post Listing 


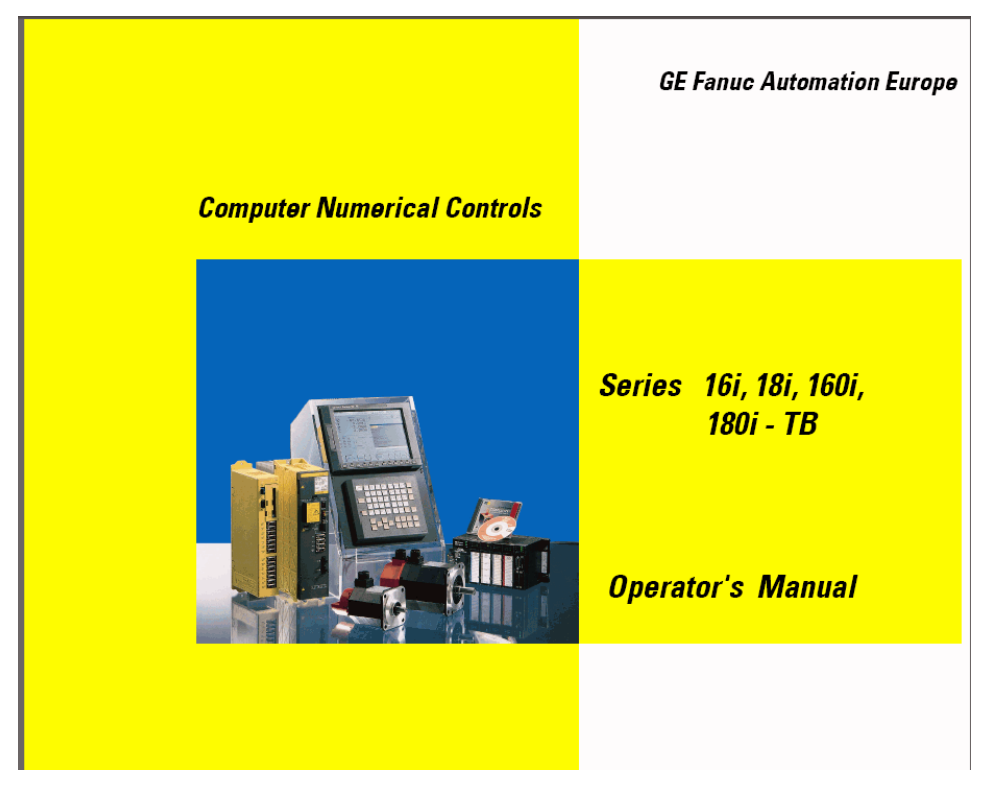

Above is an electronic copy of the Fanuc machine control operator's manual. Fanuc controls are common on many machine tools and these manuals define how codes are interpreted by the controls. Below is an electronic copy of a Heidenhain machine control users manual.

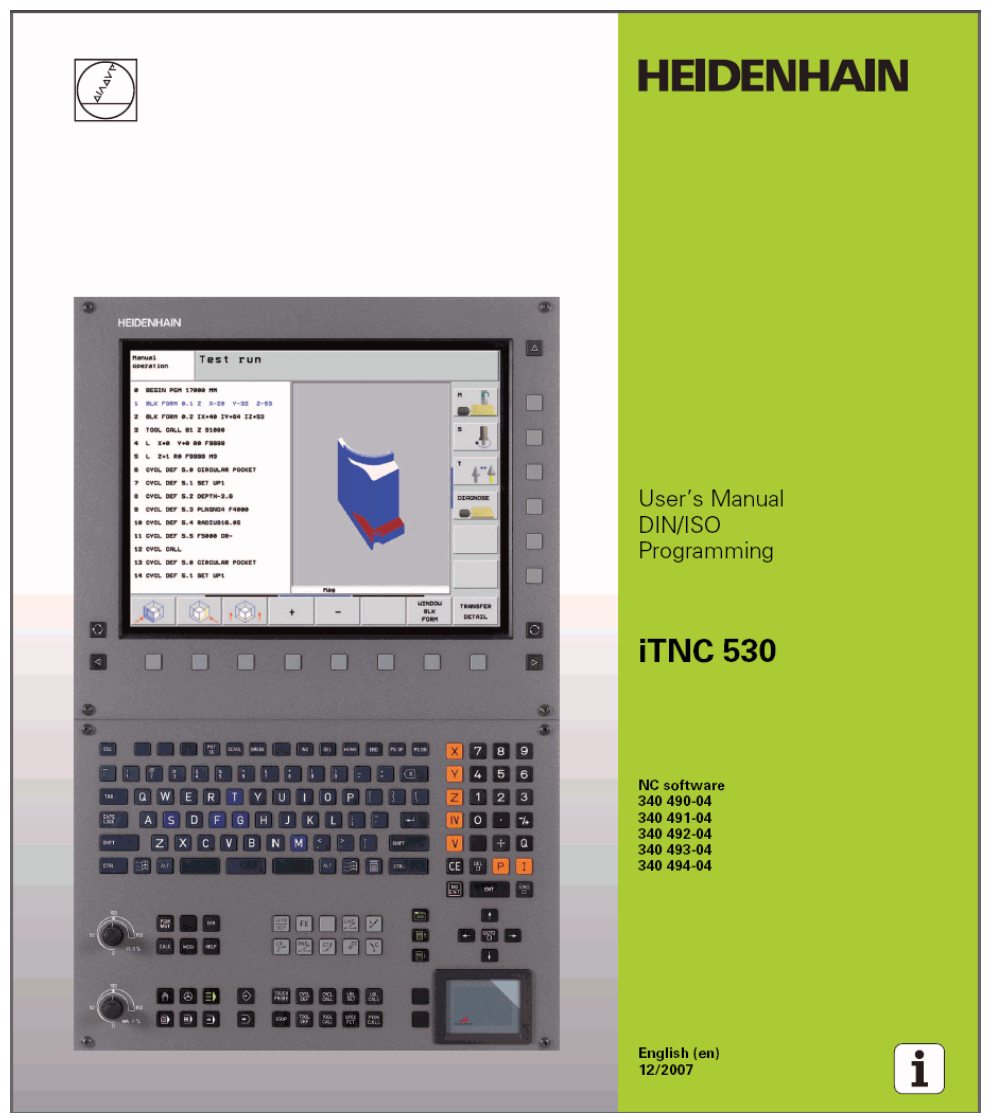


Unigraphics is the computer aided manufacturing (CAM) software used at KCP. Since all programmers are familiar with differing functions of the software, a Unigraphics users group which meets regularly has been implemented. This allows users to present and share challenges encountered and solutions to issues on a department-wide basis. This provides an open forum to proactively gain knowledge and be aware of potential pitfalls instead of trying to reactively find solutions during a crisis.

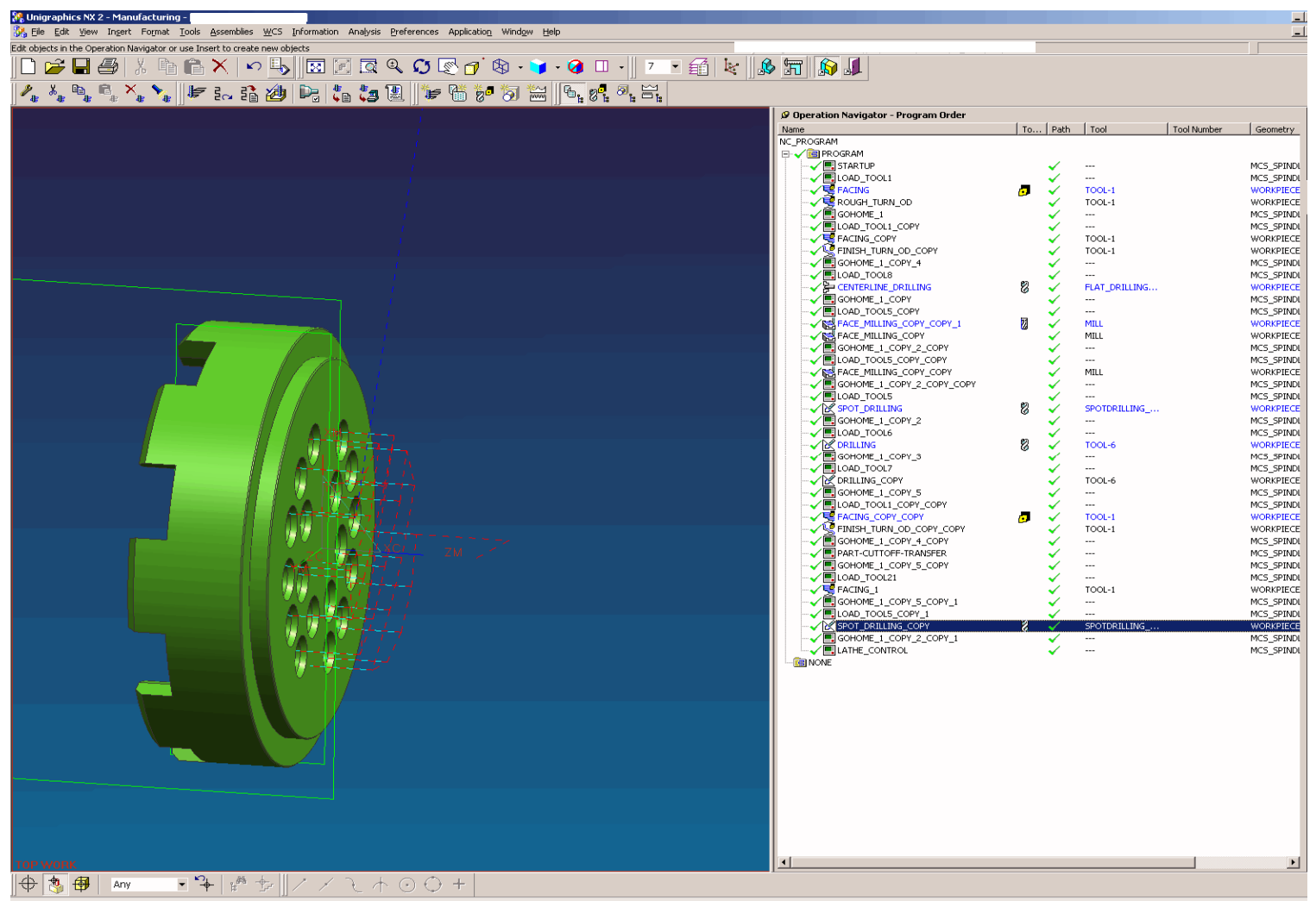

Minor procedural changes have increased efficiency but they are difficult to quantify and tedious to list. Increased collaboration with the process engineering departments and shop floor personnel are vital to the success of the program. Spending a couple of minutes of direct communication with customers can eliminate hours of unnecessary programming time by verifying the intent of the programming and eliminating or controlling any manufacturing variables.

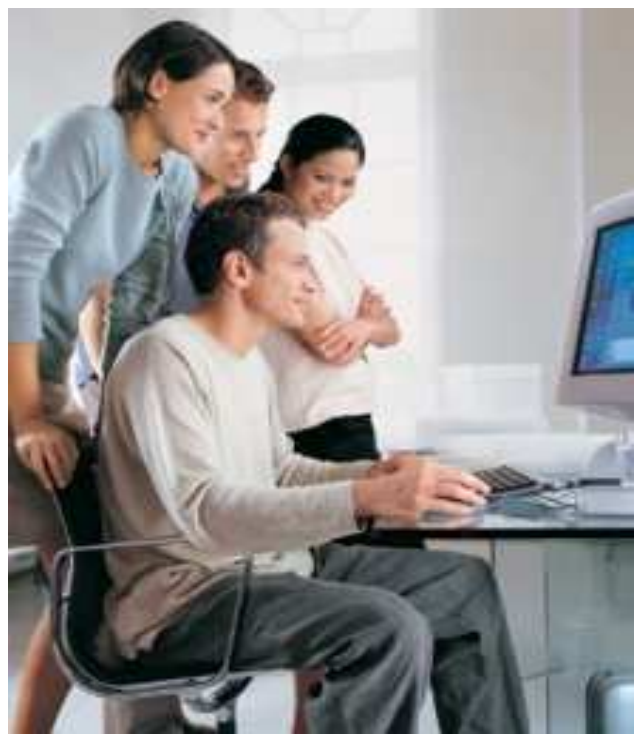


Custom part templates have also greatly increased efficiency. Using templates increases the uniformity of group programming methods making it exponentially easier for analysts to go from one program to another and be able to readily troubleshoot an issue regardless of the original author.

Custom templates are TCL scripts that tie into the Unigraphics software and allow custom commands to be coded through a graphical interface. Each program series is tied to a specific machine or type of machine. Utilizing these custom templates allows complex operations to be coded in a single graphical interface.

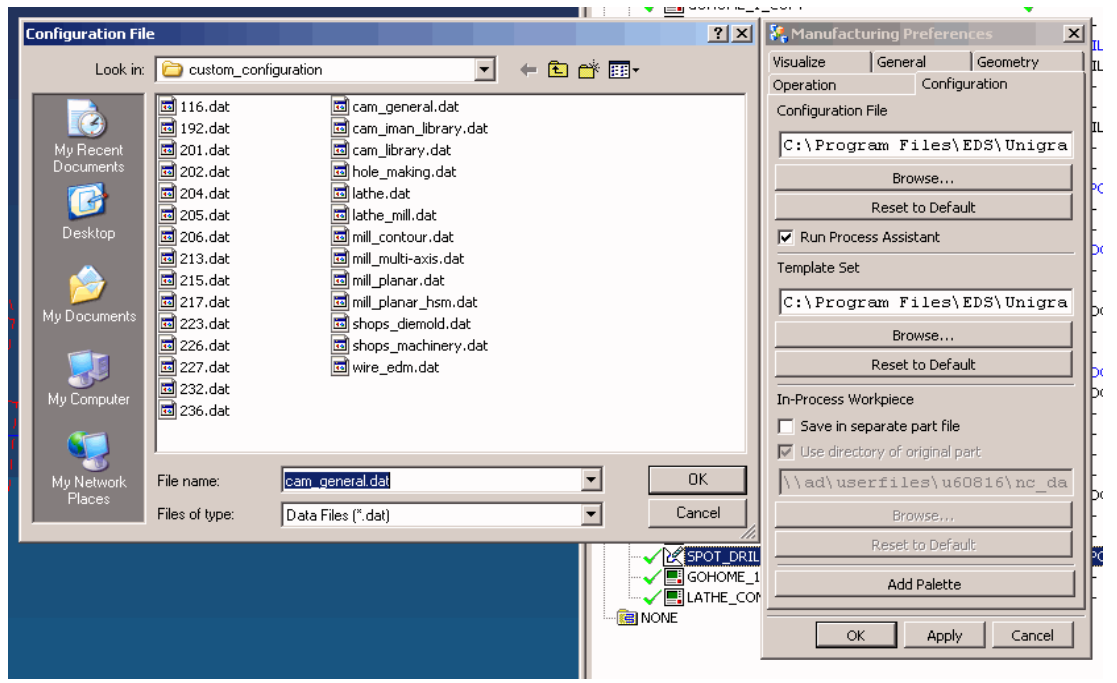


In order to stay on the cutting edge of technology we upgrade our software regularly. As with any upgrades within the complex, all changes must be carefully scrutinized to ensure that they meet our mission requirements and will generate reliable output from work done in prior editions of the software. This is done to ensure our ability to regenerate and produce parts accurately. We must maintain production capability for the life of the system. New revisions of software also lead to improvements in usability and function that simplify our work and dramatically reduce turnaround time. As a result of this subproject we will soon be completely upgraded to Unigraphics NX 6.
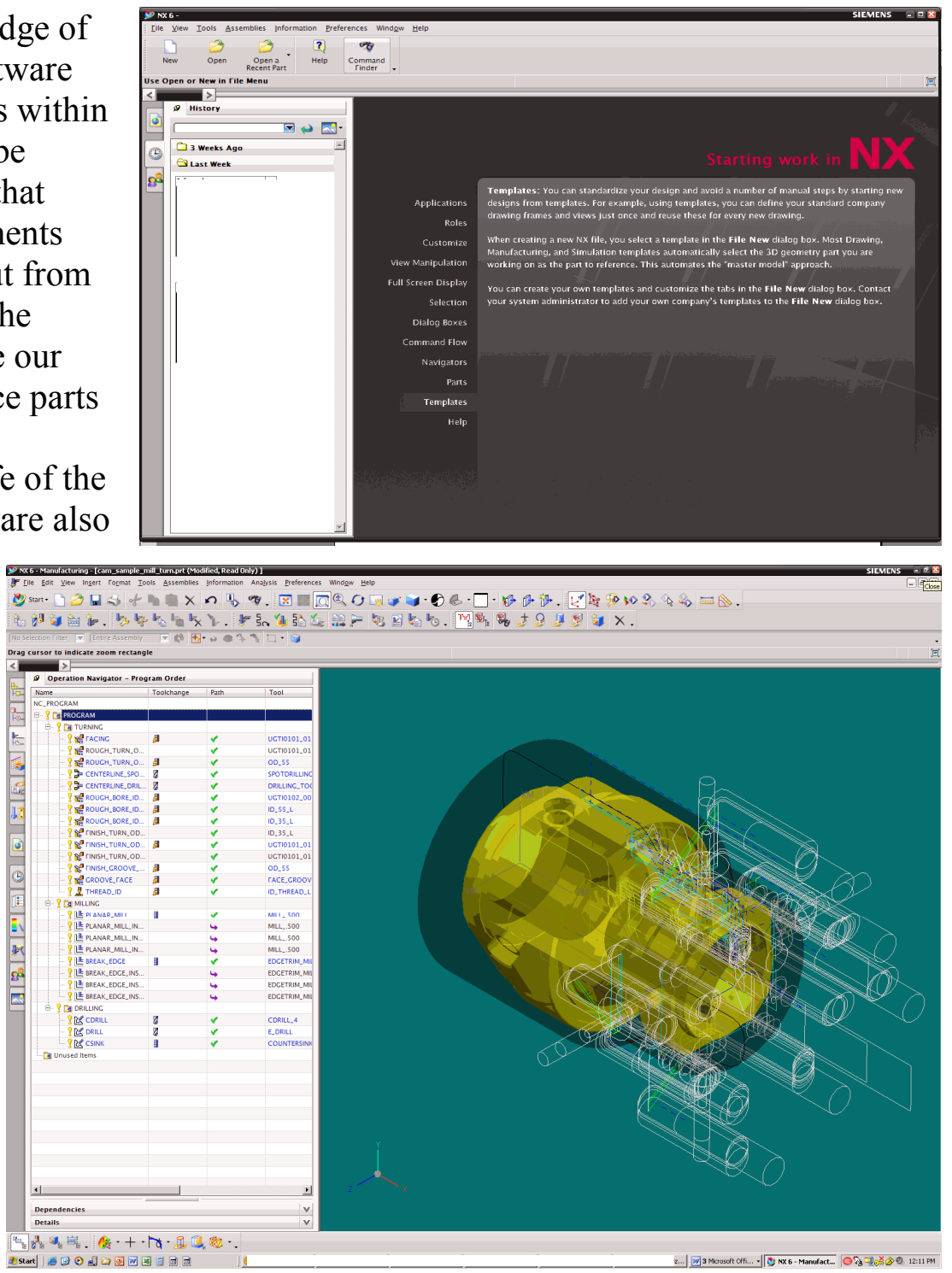


\section{Appendix D}

\section{Pallet System Study for Special Applications Machining}

Final Report/Project Accomplishments Summary

Agile Machining and Inspection Subproject 


\section{Contents}

Section Page



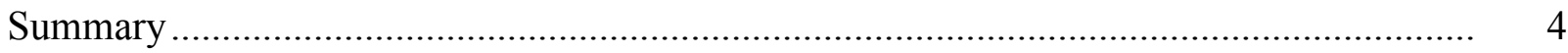

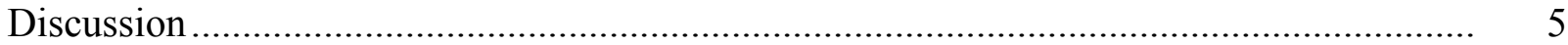

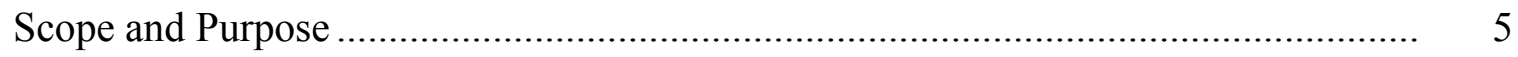

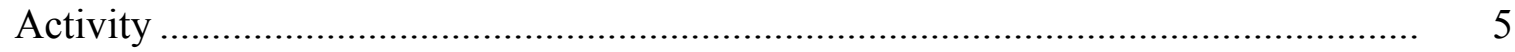

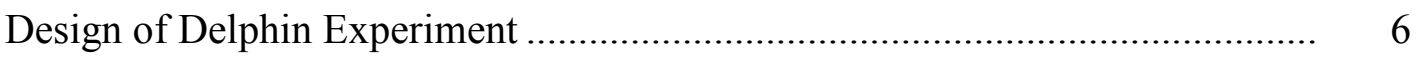

Experiment Results .................................................................... 7

Study Conclusions .......................................................................... 8

Expanding the System........................................................................... 8



Appendices

A. Minitab Data on Gage R\&R ............................................................... 11

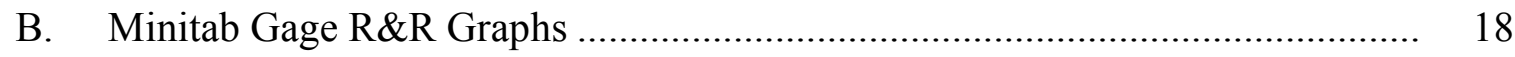

\section{Illustrations}

Figure Page

1 Ground Plate Used for Delphin Pallet System Test........................................ 7

2 Z-Touches Showing Clear Uptrend During Machine Warm-Up............................ 7

3 Base Plate with 2 Top Plates Installed on a Monarch 3-Axis Mill........................... 9 


\begin{abstract}
KCP tested a Delphin Pallet System from System $3 R$ to determine if it would have the accuracy needed to support Special Applications Machining while giving the flexibility and decreased setup time necessary to support an Agile machining area for the future.
\end{abstract}

\title{
Summary
}

The Kansas City Plant (KCP) had an interest in developing a method to facilitate faster changeover times between jobs and aid in the flexibility of equipment between shifts. The need for faster changeover times has become apparent as the facility prepares for transformation from a current 3 million square foot facility to around 1 million square feet. The new facility will house far fewer machines and will run multiple shifts. Because the KCP specializes in small volume part runs, there will be instances when one machine is needed for a first shift operation and then needed to serve an entirely different purpose on second shift. Without a method to quickly and accurately change the setup between shifts, this will prove difficult to accomplish.

One method the Kansas City Plant decided to investigate is the use of a pallet system. A pallet system is designed to allow machining jobs to be changed quickly and easily with little down time by allowing setups to attach to the machine table with quick connects.

A study was conducted on System 3R's Delphin Pallet System to test load repeatability for the pallets. A critical question for the use of pallet systems is how well the pallet repeats its position from load to load. The test was run on the department's Hermle C600U 5-Axis milling machine by using the probe to touch specified positions between loads and comparing how close the pallet came to locating in the same position as the previous load. It was found that the pallet system repeats at least as well as the probe on the department's Hermle.

With confidence that the system repeated sufficiently for our application, the Precision Machining engineering staff were queried for which machines should have pallet systems attached to them. Once the machines were identified, additional pallets were ordered and have begun use in production. In one of the first production runs, the KCP demonstrated that by using a pallet system, setup time can be reduced significantly (30 minutes vs. 4.5 hours) without a loss in accuracy. 


\section{Discussion}

\section{Scope and Purpose}

The Kansas City Plant had an interest in developing a method to facilitate faster changeover times between jobs and aid in the flexibility of equipment between shifts. The need for faster changeover times had become apparent as the facility prepares for transformation from a current 3 million square foot facility to around 1 million square feet. The new facility will house far fewer machines and will run multiple shifts. Because the KCP specializes in small volume part runs, there will be instances when one machine is needed for a first shift operation and then needed to serve an entirely different purpose on second shift. Without a method to quickly and accurately change the setup between shifts, this will prove difficult to accomplish.

The current facility does not face these problems because of excess machine capacity. The vast majority of the time there are machines available for the jobs that need to be run and setups can be left on the machine until the next time the job needs to run. Machines are dedicated to a product and only run that product. With the low volume, these machines are utilized infrequently. In the future, machines will not be dedicated to product nor even to just production. The machines will be utilized by both Production Machinists and Toolmakers, with very different setup needs. Being able to accommodate a variety of setups quickly and accurately is essential to the efficient operation of precision machining.

\section{Activity}

One method the Kansas City Plant decided to investigate is the use of a pallet system. A pallet system is designed to allow machining jobs to be changed quickly and easily with little down time by allowing setups to attach to the machine table with quick connects. The base of the pallet is fixed to the table in a known position. The pallet top-plates are mounted to fixturing, breadboards, and vices. The top-plates attach to the base in minutes and locate on the base in a known position and ready to be used.

Another benefit of the pallet system is the ability to externalize the setup of the job. While a machine is running one job, the next job can be setup on the pallet and be ready to load when the current job is complete. Pallets are primarily designed for automation and have been used with success in industry.

The pallets chosen to investigate were designed to be used for automation or for manual loading. The main characteristic for KCP's application is how accurately the pallet loads with repeated unloading and loading. If the pallet does not locate accurately, then it is not worth the effort of using.

A broad survey was performed to find out what pallet systems were available. A local vendor was contacted to present 3 systems that interested the KCP team. The Delphin, Mecatool, and Dynafix 
systems were discussed and based upon the performance stated in the manufacturer's literature, the Mecatool and Delphin systems were chosen as those best suited to our needs. A sample system was ordered from each of the manufacturers in order to quantify the real-world repeatability and reproducibility of these systems.

Rather than perform the characterization tests on both systems, the data was collected and analyzed for the Delphin system before continuing with the design and performance of the Mecatool system. The Delphin was chosen to test first because it was less expensive and not as accurate as the Mecatool system. If the Delphin system met our needs, then there was no need to investigate the more costly Mecatool system.

The Delphin pallet system is also designed to be modular. Pallet pieces can be added to the system at any time. This small scale study was done to decide if a pallet system would meet our needs on a full production scale and which pallet system should be ordered.

\section{Design of Delphin Experiment}

A study was conducted on System 3R's Delphin Pallet System to test load repeatability for the pallets. A critical question for the use of pallet systems is how well the pallet repeats its position from load to load. The operator and the engineer must be confident in the loading repeatability of the pallet for the system to function as intended.

The test was run on the department's Hermle C600U 5-Axis milling machine by using the probe to touch specified positions between loads and comparing how close the pallet came to locating in the same position as the previous load. The probe has been used in the past to verify setup and has the accuracy needed to validate the pallets. This test was run using three operators performing ten loads each and the probe taking five repeat sets of measurements each time the pallet was loaded. A ground plate was used as the pallet for the test. Two ring gages fixed to the pallet with hot glue were used to test for rotational repeatability in the XY plane. Four Z-touches (Z Ref 1-4) at the four corners of the pallet were used to test for Z-height repeatability of the pallet. A fixed reference pin was used to ensure the ring gages did not move in the glue during the test. A top view of the plate used is shown in Figure 1. 


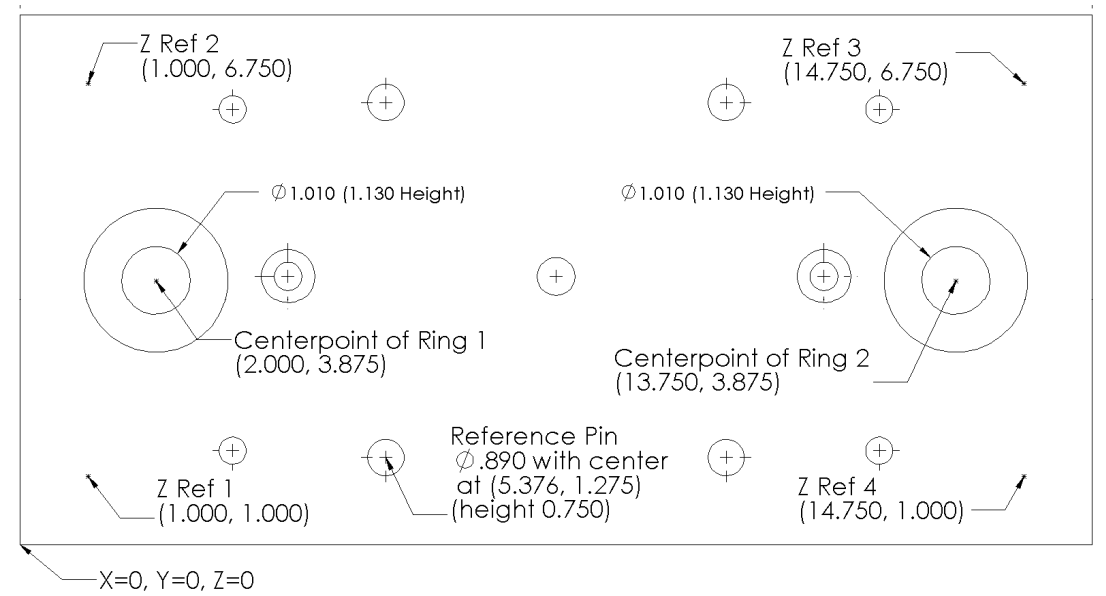

Figure 1: Ground plate used for Delphin Pallet System test

\section{$\underline{\text { Experiment Results }}$}

The test revealed several interesting facts. First, a correlation between the probe and the machines warm-up time was found to have an impact on the measurement repeatability of the probe. The magnitude of the difference in position of the pallet between loads was so small that it required the probe to measure as accurately as possible to try and distinguish differences between loads.

An example is shown below in Figure 2 of five Z-touches per load the probe took during the machine warm-up period. Data point ten was taken just before lunch and data point eleven of the next run was started after lunch about an hour later. A clear uptrend is displayed in the data while the succeeding data from the next two operators did not display this sharp uptrend, after the machine was fully warmed up.

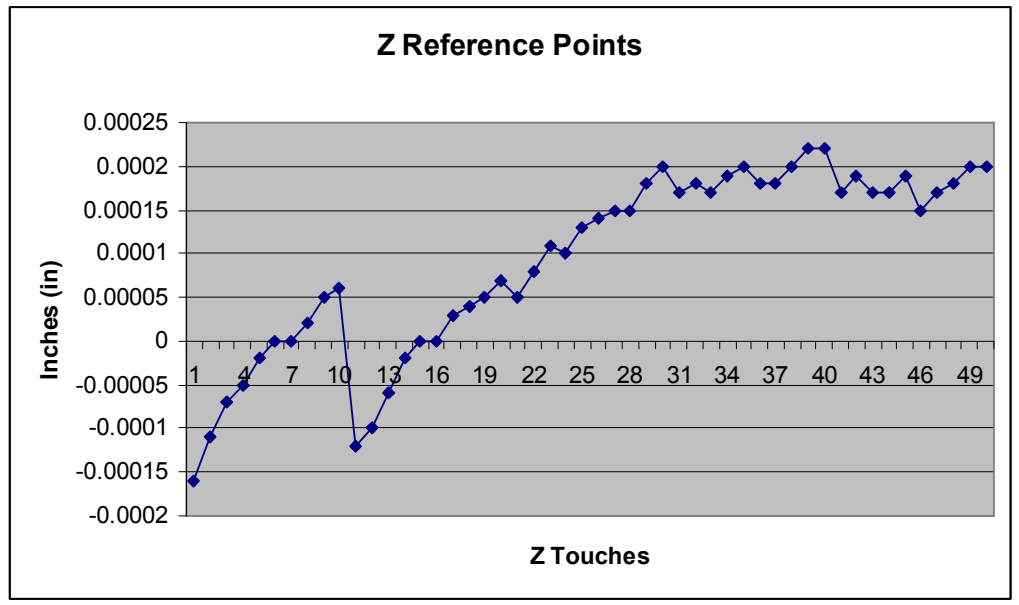

Figure 2 Z-Touches showing clear uptrend during machine warm-up.

It was interesting to find that the machine had different probe measurements depending on how much the axes had been in motion. The small changes during the warm-up period were never 
detected in setting up previous jobs because the changes are too small to contribute significantly to the effectiveness of a job setup.

A gage R\&R was performed on the data using each load as a separate part, three operators, and five repeat measurements for each load. A gage $R \& R$ was conducted on each of the measurements the probe took. For example, a gage R\&R was done on the Z Ref 1 touches, a separate one on the $Z$ Ref 2 touches, another on Ring $1 X$ coordinate and so on. The largest contributor to the variation in the study was found to be the operator. The next largest contributor was the repeatability of the probe in the Hermle. Please refer to the Appendix [attached to this appendix, Appendix D] for Gage R\&R study results.

\section{Study Conclusions}

The operator variation is believed to be caused by the difference in how well the machine is warmed up at the time the probe is used instead of actual differences in pallet location. The purpose of this experiment was to determine the repeatability of the pallet system. The gage $R \& R$ study was not able to give a concrete number for the repeatability of the pallet because the measurement system used to test the pallet was not good enough to distinguish between loads. Although this fact does not lead us to a specific number for repeatability, it does yield an important conclusion. The pallet system repeats at least as well as the probe on the department's Hermle.

The Hermle is used for multiple jobs and the probe is used to setup. This conclusion states that the Delphin pallet system will repeat sufficiently to serve the purposes of Special Applications Machining in the new facility, based upon currently forecasted work.

\section{Expanding the System}

With confidence that the system repeated sufficiently for our application, the Precision Machining engineering staff were queried for which machines should have pallet systems attached to them. The Monarch VMC 75B 3-axis mills (4), the Dixie 5-axis mill (1), the Hermle C40U 5-axis mills (2), the Hermle C600U 5-axis mills (3), and the Monarch VMC 175-B 3-axis mill were chosen as good candidates for the pallets. The 3 -axis machines are time consuming to setup fixturing square to the movement of the table. By having a pallet base already dialed in, setup of a fixture can be reduced from a couple of hours to $\sim 15$ minutes. The 5 -axis mills benefit from the pallets by raising the sides of the work table closer to the spindle and away from the rotary table. A pallet system with 2 top plates is shown in Figure 3. 


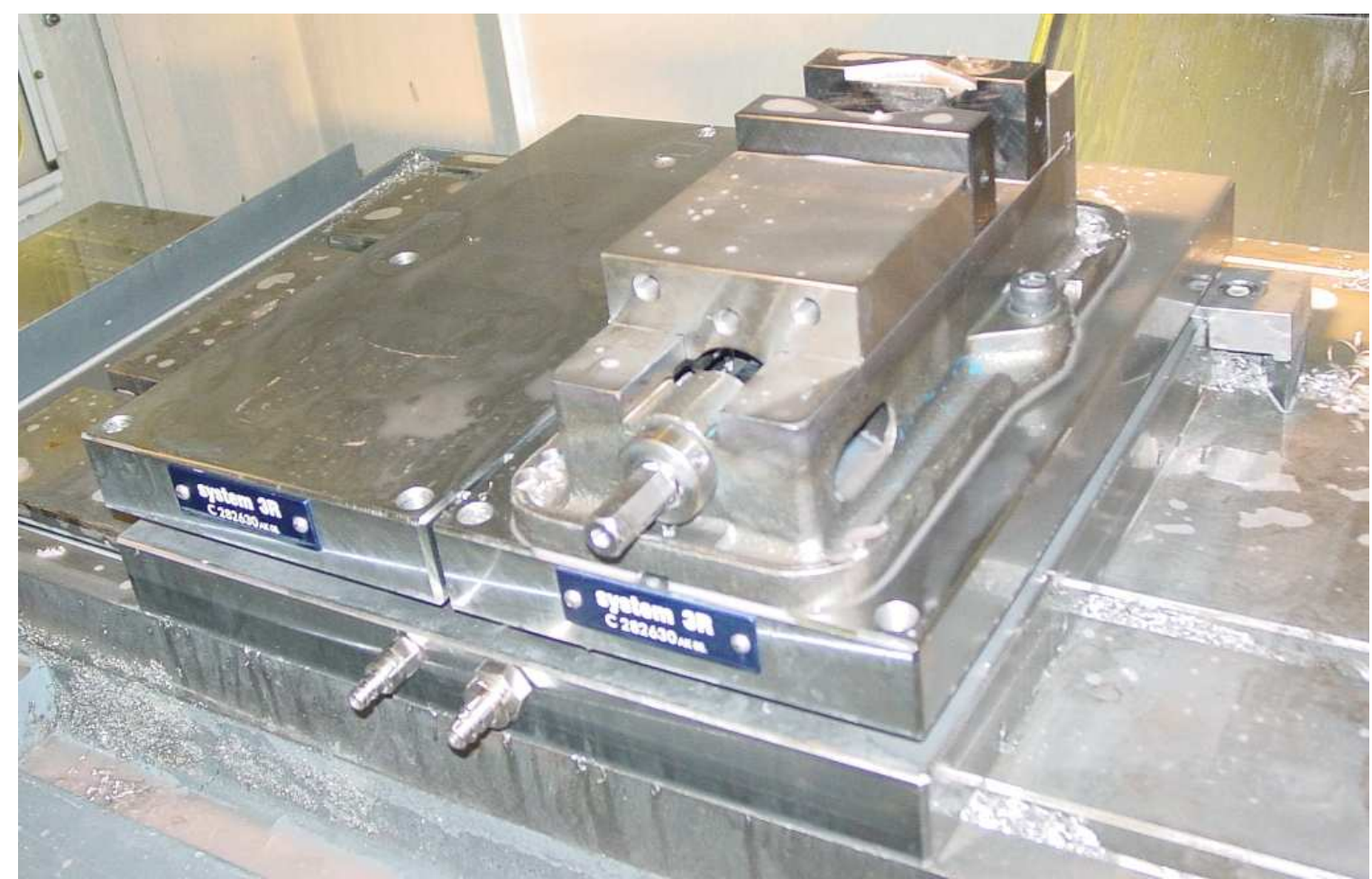

Fig. 3 Base plate with 2 top plates installed on a Monarch 3-axis mill.

Systems for the identified machines were ordered through a local distributor. Pallet bases were ordered for all machines. 4 top plates were ordered pre-fabricated, with connectors ordered for another 16 units. The connectors will be used with existing fixtures with no top plate needed. Control boxes were ordered with each of the systems. The control box allows the air lines to remain connected to the pallet base during the loading and unloading of the top plates.

Installation on all machines will be completed as production schedules allow, however initial production testing with the pallets on a Monarch showed a reduction in setup time from 4.5 hours down to less than 30 minutes. This setup reduction is critical as we transition to an Agile machining environment where machines may run different parts on each shift. The reduction in setup time also increases the utilization time of the machine. The less time spent indicating in fixturing, the more time the spindle can be running and cutting chips. This will support more aggressive schedules and allow manufacturing to be more flexible to changes. 


\section{Accomplishments}

The KCP demonstrated that by using a pallet system, setup time can be reduced significantly (30 minutes vs. 4.5 hours) without a loss in accuracy. KCP also prepared for the future by purchasing a pallet system that increases the utilization and flexibility of our mills in Precision Machining. Utilization is increased by reducing idle time of the spindle. Flexibility is increased by a reduction in setup time. This reduction makes it quicker and less expensive to stop and change jobs. For the intricate parts with small lot sizes that KCP specializes in, a large portion of the cost of the parts is setup and dialing in the first piece. The pallets minimize this cost by removing much of the manual labor from the setup. This change in process will better prepare Precision Machining to transform into an Agile Special Applications Machining area in the new facility. 


\section{Gage R\&R Study - ANOVA Method}

Gage R\&R for Z Ref 2

Gage name: Delphin Pallet study on Hermle

Date of study: 4/9/07-4/10/07

Tolerance:

Misc:

\section{Two-Way ANOVA Table With Interaction}

$\begin{array}{lrrrrr}\text { Source } & \text { DF } & \text { SS } & \text { MS } & \text { F } & \text { P } \\ \text { Pallet Load } & 9 & 0.0000000 & 0.0000000 & 2.526 & 0.045 \\ \text { Operator } & 2 & 0.0000009 & 0.0000005 & 267.564 & 0.000 \\ \text { Pallet Load * Operator } & 18 & 0.0000000 & 0.0000000 & 6.577 & 0.000 \\ \text { Repeatability } & 120 & 0.0000000 & 0.0000000 & & \\ \text { Total } & 149 & 0.0000010 & & & \end{array}$

\section{Gage R\&R}

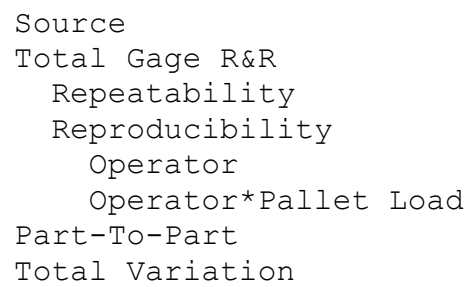

Total Variation

Number of Distinct Categories $=1$

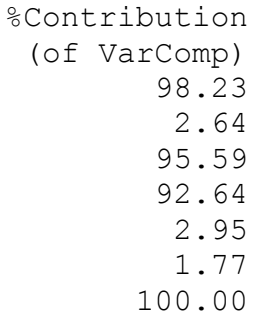

$0.0005910 \quad 100.00$

\section{Gage R\&R for Z Ref 2}




\section{Gage R\&R Study - ANOVA Method}

Gage R\&R for Z Ref 3

Gage name: Delphin Pallet study on Hermle

Date of study: 4/9/07-4/10/07

Tolerance:

Misc:

\section{Two-Way ANOVA Table With Interaction}

$\begin{array}{lrrrrr}\text { Source } & \text { DF } & \text { SS } & \text { MS } & \text { F } & \text { P } \\ \text { Pallet Load } & 9 & 0.0000001 & 0.0000000 & 4.708 & 0.003 \\ \text { Operator } & 2 & 0.0000004 & 0.0000002 & 145.101 & 0.000 \\ \text { Pallet Load * Operator } & 18 & 0.0000000 & 0.0000000 & 5.801 & 0.000 \\ \text { Repeatability } & 120 & 0.0000000 & 0.0000000 & & \\ \text { Total } & 149 & 0.0000005 & & & \end{array}$

\section{Gage R\&R}

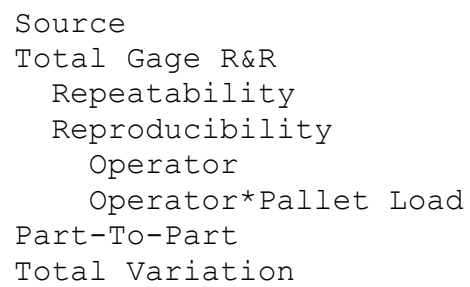

Total Variation

Number of Distinct Categories $=1$

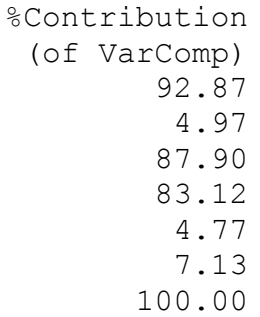

\section{Gage R\&R for Z Ref 3}




\section{Gage R\&R Study - ANOVA Method}

Gage R\&R for Z Ref 4

Gage name: Delphin Pallet study on Hermle

Date of study: 4/9/07-4/10/07

Tolerance:

Misc:

\section{Two-Way ANOVA Table With Interaction}

$\begin{array}{lrrrrr}\text { Source } & \text { DF } & \text { SS } & \text { MS } & \text { F } & \text { P } \\ \text { Pallet Load } & 9 & 0.0000001 & 0.0000000 & 5.921 & 0.001 \\ \text { Operator } & 2 & 0.0000004 & 0.0000002 & 152.568 & 0.000 \\ \text { Pallet Load * Operator } & 18 & 0.0000000 & 0.0000000 & 4.006 & 0.000 \\ \text { Repeatability } & 120 & 0.0000000 & 0.0000000 & & \\ \text { Total } & 149 & 0.0000005 & & & \end{array}$

\section{Gage R\&R}

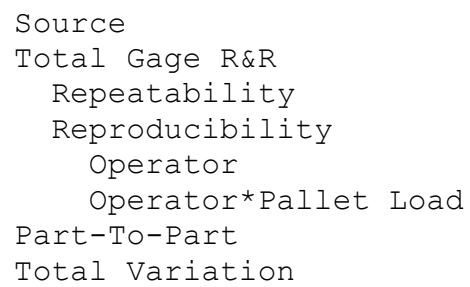

Total Variation

Number of Distinct Categories $=1$

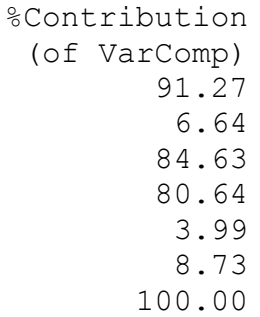

\section{Gage R\&R for Z Ref 4}




\section{Gage R\&R Study - ANOVA Method}

Gage R\&R for Ring $1 \mathrm{X}$

Gage name: Delphin Pallet Study on Hermle

Date of study: 4/9/07-4/10/07

Tolerance:

Misc:

\section{Two-Way ANOVA Table With Interaction}

$\begin{array}{lrrrrr}\text { Source } & \text { DF } & \text { SS } & \text { MS } & \text { F } & \text { P } \\ \text { Pallet Load } & 9 & 0.0000002 & 0.0000000 & 3.8238 & 0.007 \\ \text { Operator } & 2 & 0.0000003 & 0.0000002 & 36.8977 & 0.000 \\ \text { Pallet Load * Operator } & 18 & 0.0000001 & 0.0000000 & 38.9408 & 0.000 \\ \text { Repeatability } & 120 & 0.0000000 & 0.0000000 & & \\ \text { Total } & 149 & 0.0000006 & & & \end{array}$

\section{Gage R\&R}

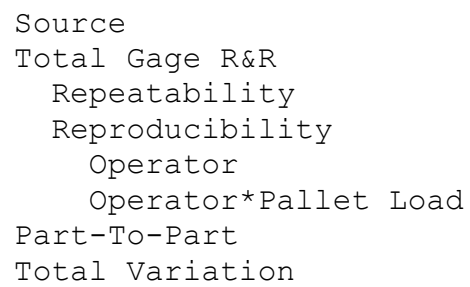

Total Variation

Number of Distinct Categories $=1$

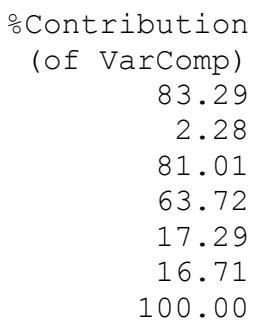

$0.0004299 \quad 100.00$

\section{Gage R\&R for Ring 1 X}




\section{Gage R\&R Study - ANOVA Method}

Gage $R \& R$ for Ring $1 \mathrm{Y}$

Gage name: Delphin Pallet Study on Hermle

Date of study: 4/9/07-4/10/07

Tolerance:

Misc:

\section{Two-Way ANOVA Table With Interaction}

$\begin{array}{lrrrrr}\text { Source } & \text { DF } & \text { SS } & \text { MS } & \text { F } & \text { P } \\ \text { Pallet Load } & 9 & 0.0000000 & 0.0000000 & 0.8920 & 0.551 \\ \text { Operator } & 2 & 0.0000000 & 0.0000000 & 25.8378 & 0.000 \\ \text { Pallet Load * Operator } & 18 & 0.0000000 & 0.0000000 & 5.2979 & 0.000 \\ \text { Repeatability } & 120 & 0.0000000 & 0.0000000 & & \\ \text { Total } & 149 & 0.0000001 & & & \end{array}$

\section{Gage R\&R}



Total Variation

Number of Distinct Categories $=1$

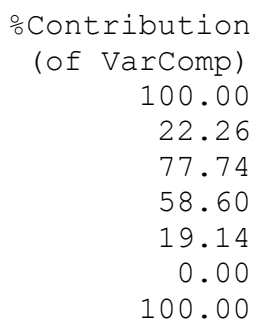

\section{Gage R\&R for Ring $1 Y$}




\section{Gage R\&R Study - ANOVA Method}

Gage R\&R for Ring $2 \mathrm{X}$

Gage name: Delphin Pallet Study on Hermle

Date of study: 4/9/07-4/10/07

Tolerance:

Misc:

\section{Two-Way ANOVA Table With Interaction}

$\begin{array}{lrrrrr}\text { Source } & \text { DF } & \text { SS } & \text { MS } & \text { F } & \text { P } \\ \text { Pallet Load } & 9 & 0.0000000 & 0.0000000 & 0.8053 & 0.617 \\ \text { Operator } & 2 & 0.0000001 & 0.0000000 & 19.7232 & 0.000 \\ \text { Pallet Load * Operator } & 18 & 0.0000000 & 0.0000000 & 19.6818 & 0.000 \\ \text { Repeatability } & 120 & 0.0000000 & 0.0000000 & & \\ \text { Total } & 149 & 0.0000001 & & & \end{array}$

\section{Gage R\&R}

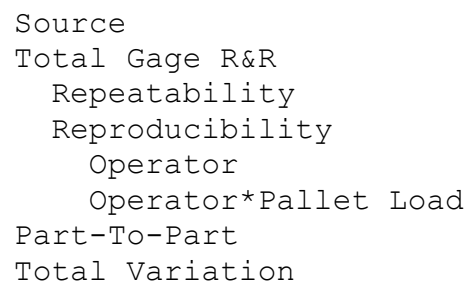

Total Variation

Number of Distinct Categories $=1$

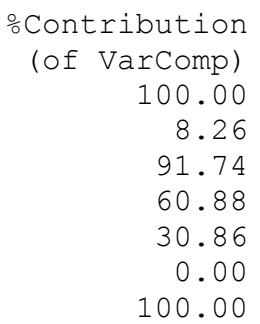

\section{Gage R\&R for Ring 2 X}




\section{Gage R\&R Study - ANOVA Method}

Gage R\&R for Ring $2 \mathrm{Y}$

Gage name: Delphin Pallet Study on Hermle

Date of study: 4/9/07-4/10/07

Tolerance:

Misc:

\section{Two-Way ANOVA Table With Interaction}

$\begin{array}{lrrrrr}\text { Source } & \text { DF } & \text { SS } & \text { MS } & \text { F } & \text { P } \\ \text { Pallet Load } & 9 & 0.0000000 & 0.0000000 & 2.1620 & 0.078 \\ \text { Operator } & 2 & 0.0000000 & 0.0000000 & 13.4076 & 0.000 \\ \text { Pallet Load * Operator } & 18 & 0.0000000 & 0.0000000 & 2.6857 & 0.001 \\ \text { Repeatability } & 120 & 0.0000000 & 0.0000000 & & \\ \text { Total } & 149 & 0.0000001 & & & \end{array}$

\section{Gage R\&R}

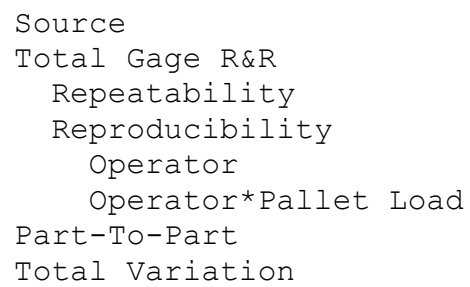

Total Variation

Number of Distinct Categories $=1$

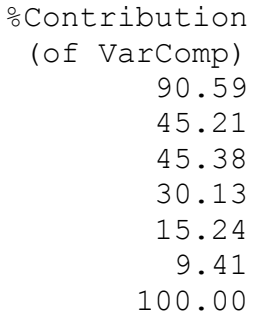

Gage $R \& R$ for Ring 2 Y 


\section{Appendix B: Minitab Gage R\&R Graphs [Part of Appendix D Report]}

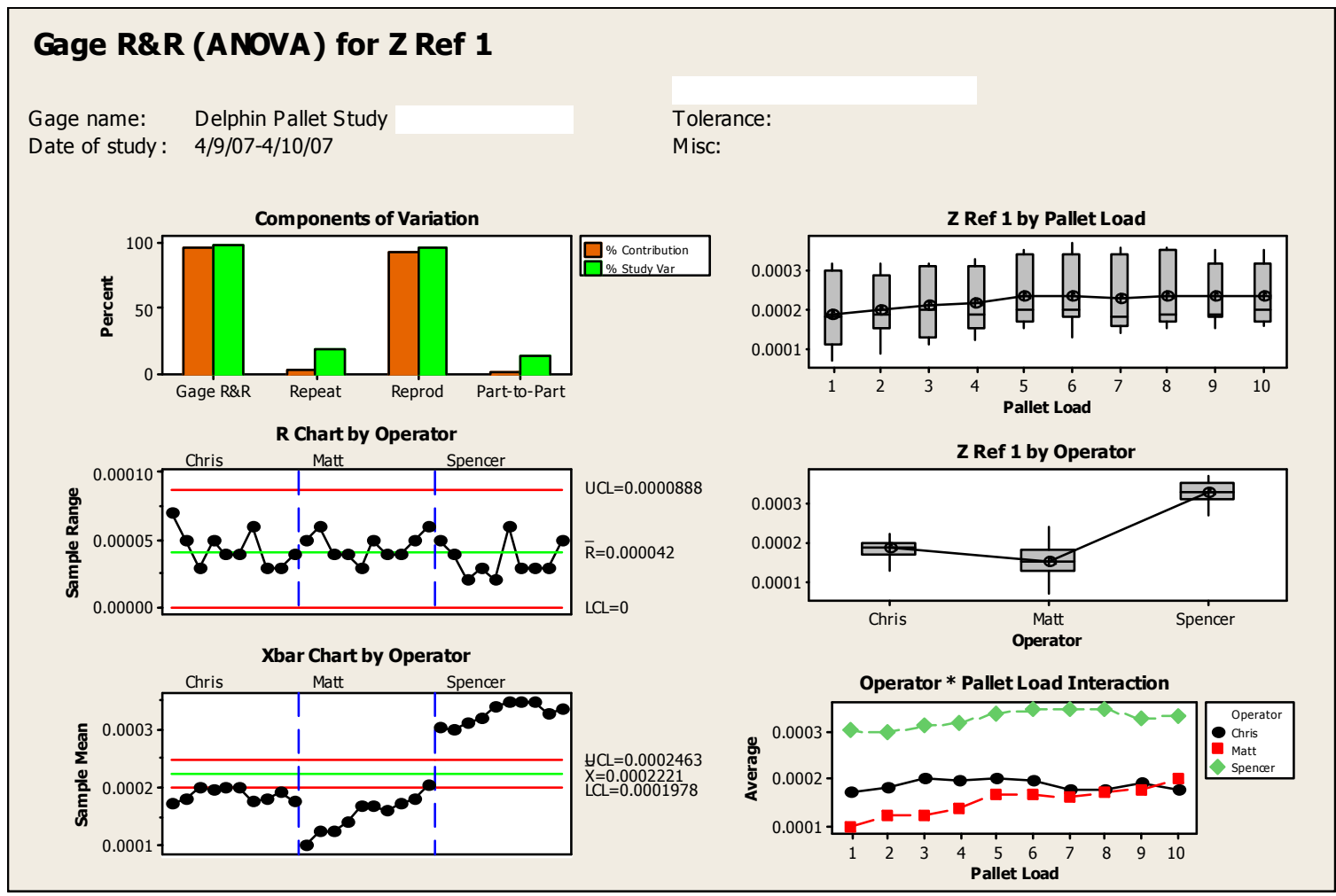




\section{Gage R\&R (ANOVA) for Z Ref 2}

Gage name: Delphin Pallet Study

Date of study: $\quad 4 / 9 / 07-4 / 10 / 07$
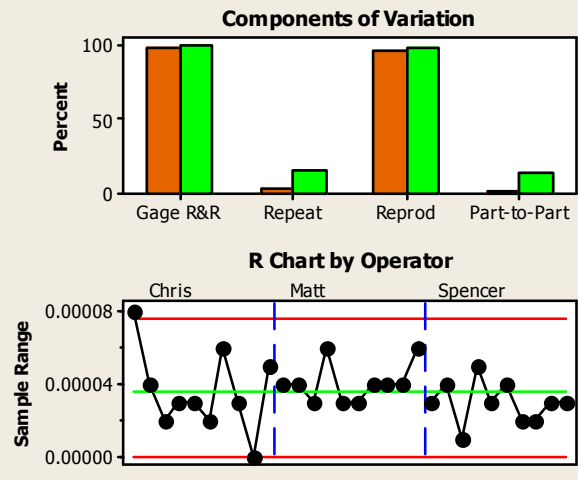

Xbar Chart by Operator

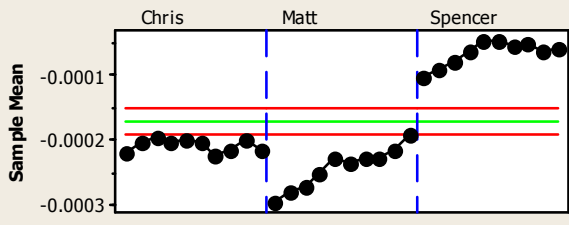

Tolerance:

Misc:
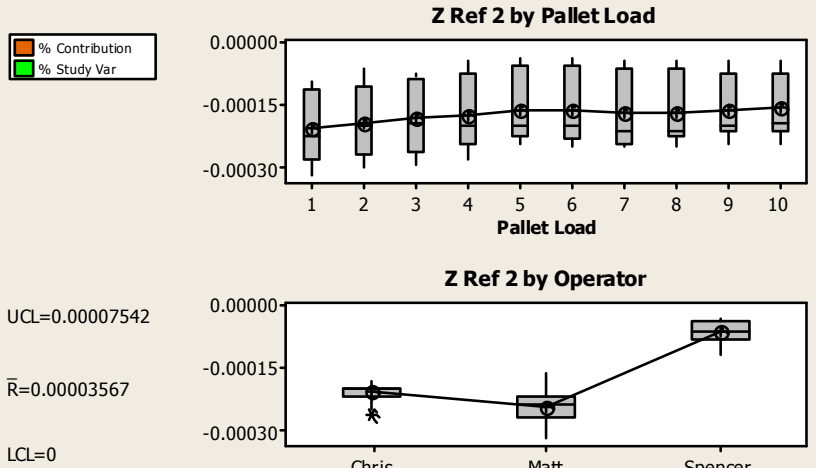

Z Ref 2 by Operator
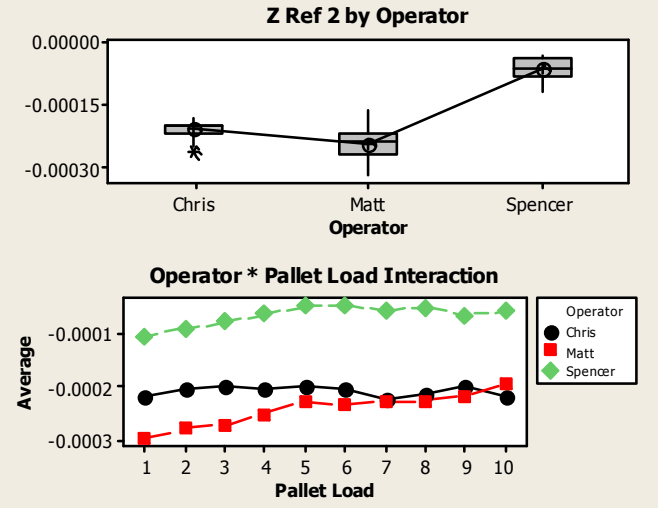

\section{Gage R\&R (ANOVA) for Z Ref 3}

Gage name: Delphin Pallet Study

Date of study: $\quad 4 / 9 / 07-4 / 10 / 07$
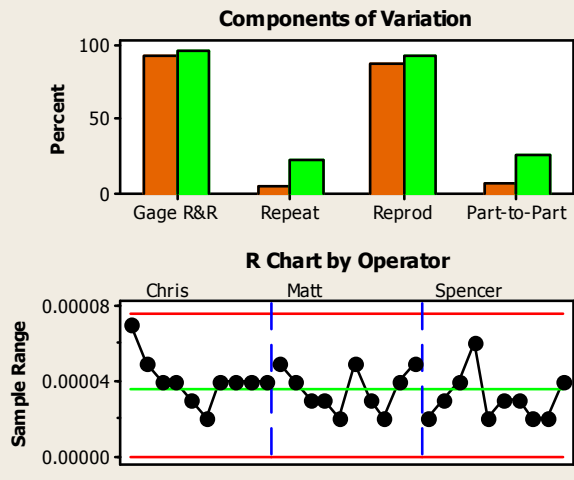

Xbar Chart by Operator



Tolerance:

Misc:



Z Ref 3 by Operator



Operator * Pallet Load Interaction

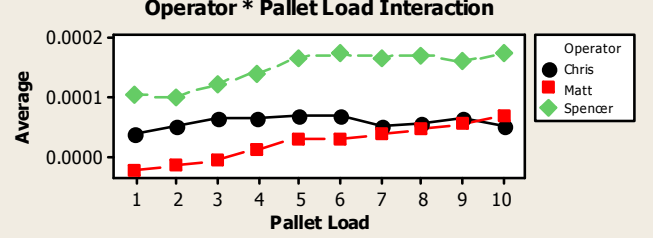




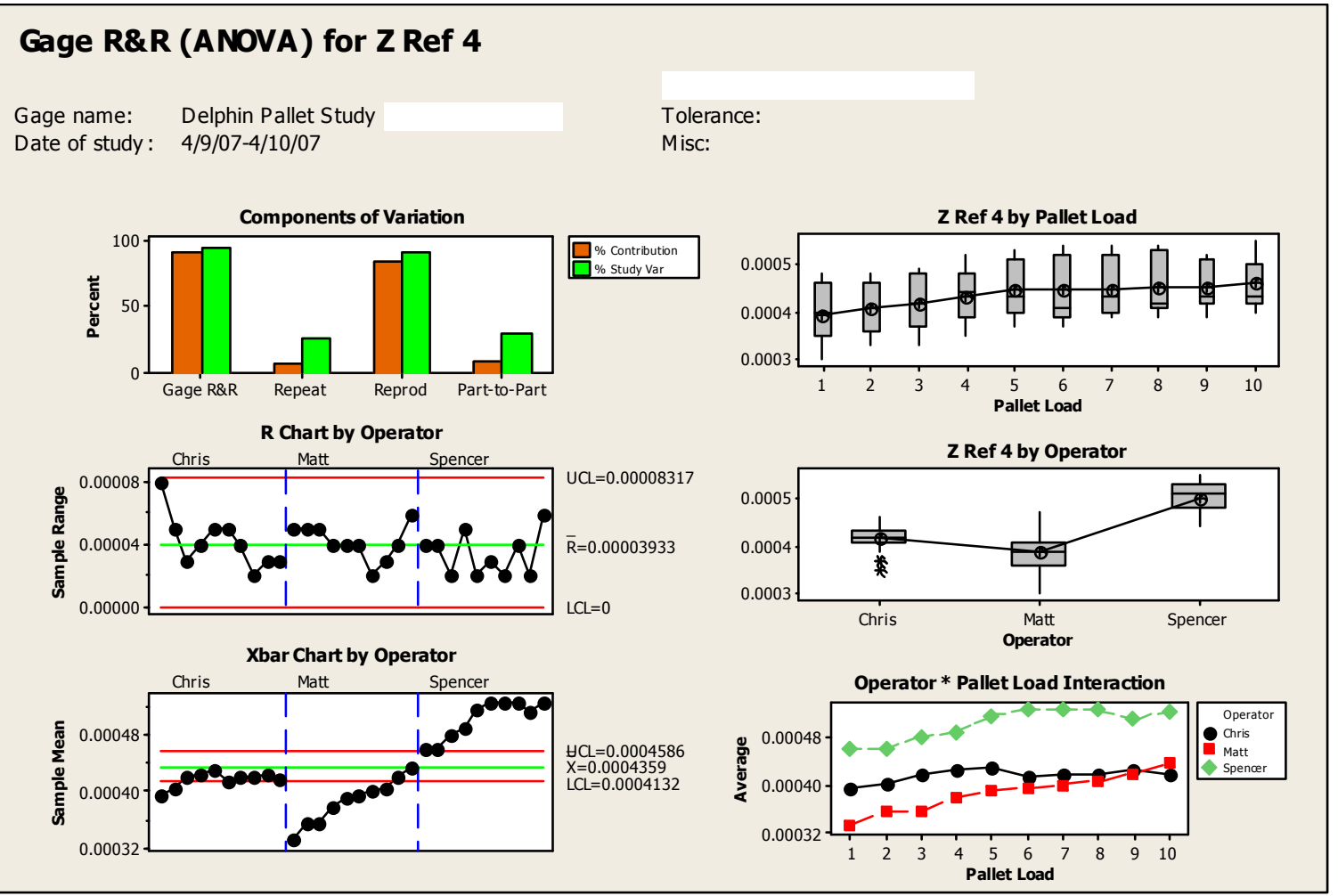

\section{Gage R\&R (ANOVA) for Ring $1 \mathrm{X}$}

Gage name: Delphin Pallet Study

Date of study: $\quad 4 / 9 / 07-4 / 10 / 07$


Xbar Chart by Operator

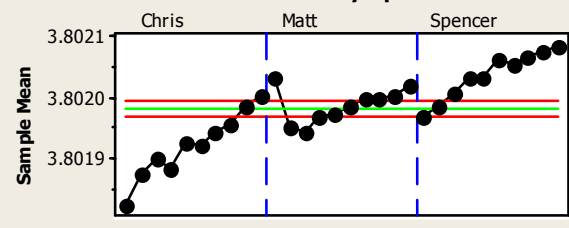

Tolerance:

Misc:

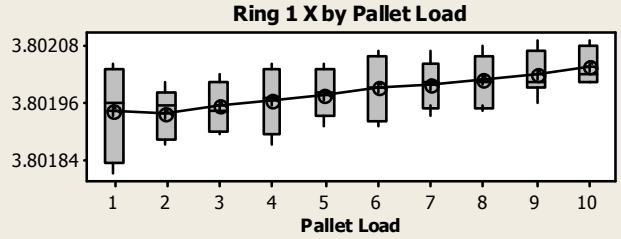

Ring $1 \mathrm{X}$ by Operator
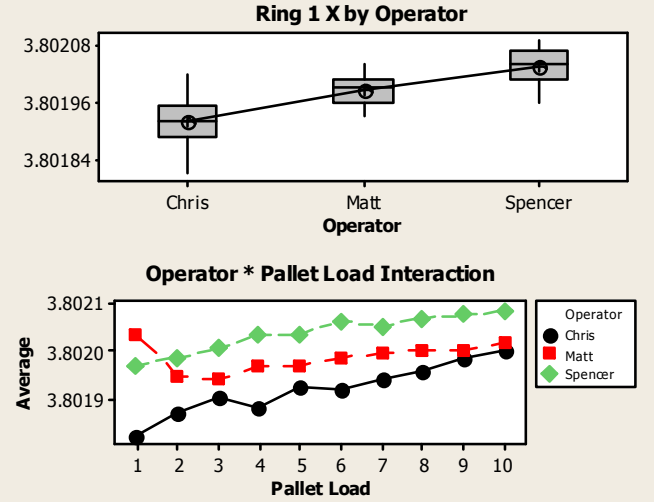


\section{Gage R\&R (ANOVA) for Ring 1 Y}

Gage name: Delphin Pallet Study

Date of study: $\quad 4 / 9 / 07-4 / 10 / 07$


Xbar Chart by Operator
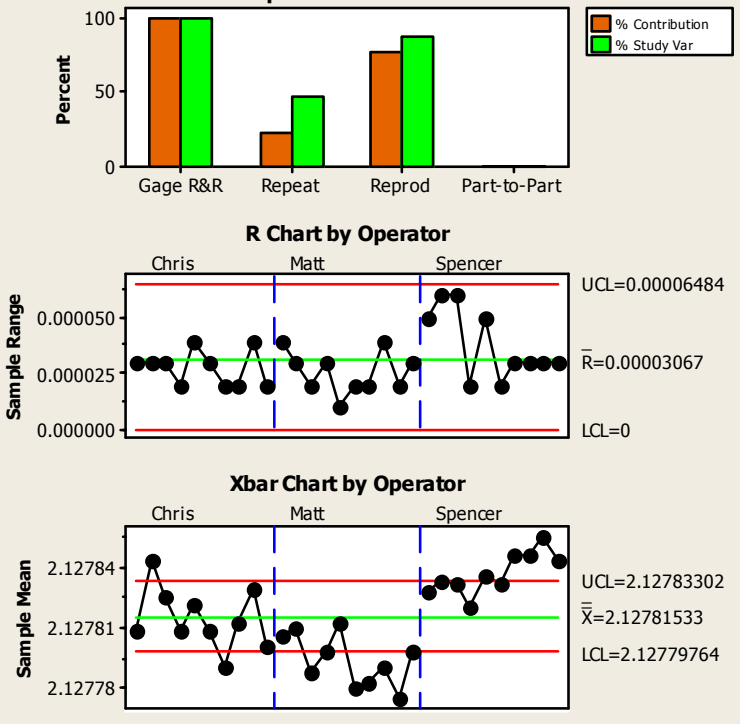

$\mathrm{UCL}=2.1278330$ $\overline{\bar{X}}=2.12781533$ $\mathrm{LCL}=2.12779764$
Tolerance:

Misc:



Ring 1 Y by Operator
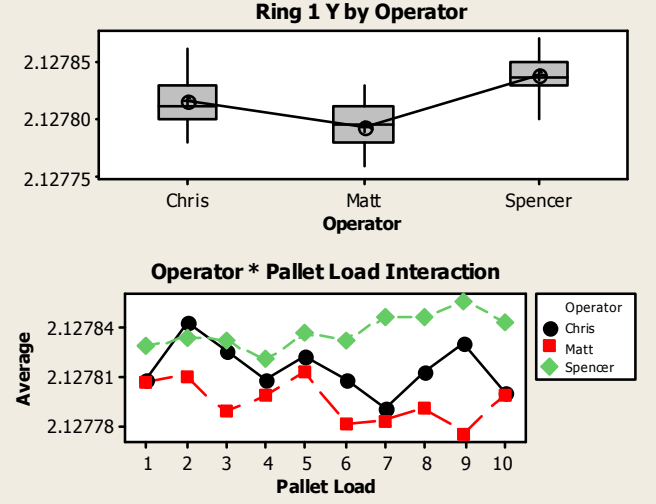

\section{Gage R\&R (ANOVA) for Ring 2 X}

Gage name: Delphin Pallet Study

Date of study: $\quad 4 / 9 / 07-4 / 10 / 07$


Xbar Chart by Operator

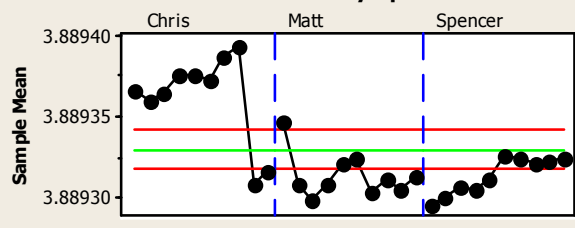

Tolerance:

Misc:



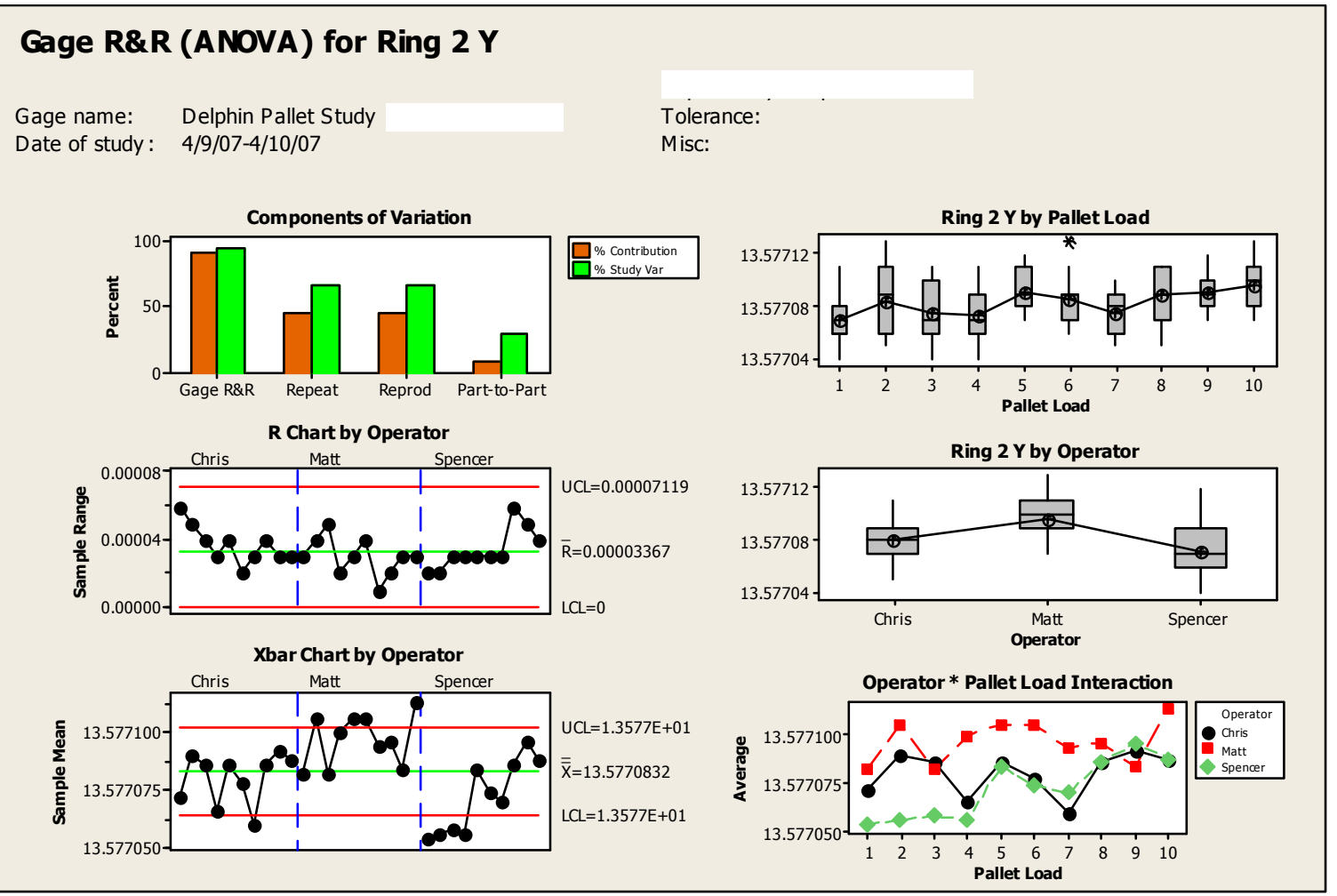

